\title{
MÁS DEPENDIENTE Y MENOS COMPETENTE: EL NUEVO SENADO BELGA DE COMUNIDADES Y REGIONES TRAS LA REFORMA CONSTITUCIONAL
}

\author{
JUAN JOSÉ RUIZ RUIZ \\ Profesor Titular de Derecho Constitucional \\ Universidad de Jaén
}

\section{SUMARIO}

I. Introducción. II. La nueva composición. III. La pérdida de competencias legislativas. IV. La indisolubilidad ordinaria del nuevo Senado y los períodos de sesiones. V. Reducción de otras competencias. VI. Conclusiones.

\section{INTRODUCCIÓN}

Los frecuentes cambios a los que viene estando sometido el federalismo belga han hecho que la definición que mejor se adapta a sus características sea la de una forma federal sumida en una incesante construcción ${ }^{1}$, o permanentemente in fie$r i^{2}$, de ahí que hasta la Constitución de 1993 era más propio hablar de voie fédérale (vía federal) que de federalismo en sî́ ${ }^{\wedge}$, pues ha sido construido a impulsos de las presiones nacionalistas e identitarias ${ }^{4}$. Ello ha dado pie a un federalismo de desagregación que tiene su manifestación más extrema en la inexistencia de partidos políticos nacionales 5 . Otro factor no menor y que aporta originalidad, pero tam-

1 En ello han tenido mucho que ver los sucesivos compromisos alcanzados según la relación de fuerzas. Cfr. E. Lentzen, «Le processus de fédéralisation», M. Martiniello - M. Swyngedouw (ed.), Où va la Belgique?. Les soubresauts d'une petite démocratie européenne, Paris, L'Harmattan, 1998, p. 43.

2 Hasta 2010 cinco grandes reformas institucionales habían tenido lugar: 1980, 1988-1989, 1993 y 2001.Cfr. BeAufays, J. et MATAGne, «Fédéralisation et structures institutionnelles: la Belgique entre refondation et liquidation» ID. (ed.), La Belgique en mutation. 1968-2008, Bruxelles, Bruylant, 2009, pp. 9-48.

3 Cfr. X. Mabille, «La faille du compromis», M. Uyttendaele (comp.), «A l'enseigne de la Belgique nouvelle», Revue de l'Université de Bruxelles, 1989/3-4 (número monográfico), p. 65.

4 Cfr. K. Deprez and Louis Vos (ed.), Nationalism in Belgium: shifting identities, 1780-1995, Macmillan, New York, 1998.

5 Cfr. R. Dandoy - N. De Decker, «Peut-on encore parler de «partis frères» en Belgique?», Pilet J.-B., De Waele J.-M., Jaumain S., L'absence de partis nationaux: menace ou opportunité?, Editions de l'Univer- 
bién inestabilidad al régimen constitucional belga es el del permanente carácter constituyente de sus cámaras desde 1978, haciendo que lo que hasta entonces era excepcional se haya convertido a la postre en regla ${ }^{6}$. El Senado belga no solo no ha sido desde luego ajeno a estas transformaciones, sino que en todas y cada una de las revisiones constitucionales que han tenido lugar desde 1831 su composición ha sido siempre objeto de modificación ${ }^{7}$.

En medio de una crisis política e institucional tras las elecciones legislativas federales de 2010, los acuerdos post-electorales y de formación de gobierno forjaron, tras 541 días de negociaciones para formar una coalición de gobierno, el Acuerdo institucional para la sexta reforma del Estado de 11 de octubre de 2011, cuya traducción normativa ha entrañado una reforma constitucional y legislativa de amplio espectro que ha incidido en numerosos aspectos de la organización territorial e institucional. La complejidad técnica de la reforma ha exigido no solo instrumentarla en dos tiempos, sino que además se ha procedido a reformar el art. 195 de la Constitución belga (en adelante, CB), precepto que disciplina la reforma constitucional, con efectos transitorios solo para esta ocasión ${ }^{8}$. El acuerdo contemplaba que el Senado será adaptado a la nueva estructura del Estado para transformarlo en una cámara de los entes federados.

El objetivo perseguido con esta reforma del Senado según la exposición de motivos es el de garantizar la participación de los parlamentos de los entes federados a la organización y funcionamiento fundamentales del Estado federal, así como crear un vínculo real de encuentro para los Parlamentos de Comunidad y de Región. El resultado obtenido, a la luz de los primeros estudios doctrinales, dista sin embargo de haber cumplido con este objetivo.

La pretensión de crear un Senado de Comunidades y de Regiones estaba incluida en una negociación de más amplio alcance, en el que figuraban otras cuestiones como la escisión de la circunscripción de Bruxelles-Hal-Vilvorde (en adelante, BHV) o la refinanciación de Bruselas, pero con el Acuerdo no se zanjaron todos los detalles. Por este motivo se hizo encargo a un grupo de trabajo para que precisara los principios de la reforma. Este grupo se componía de 8 senadores

sité de Bruxelles, Bruxelles, 2009, pp. 19-35

6 A excepción de la Legislatura 1982-1985. Cfr. M. UytTEndaele, Les institutions de la Belgique, Éditions Larcier, Bruxelles, 2014, p. 18.

7 Cfr. P. Delwit, J.-M. De Waele, P. Magnette (dir.), Gouverner la Belgique, Paris, PUF, 1999.

8 En puridad sin embargo, la revisión del art. 195 CB (publicada el 6 de abril de 2012) no modificaba su redacción, sino que se le adicionaba una disposición transitoria o art. 195 transitorio de quince apartados cuya eficacia se agotaba por tanto uno actu y que fue declarada conforme a Constitución por el Dictamen de la Comisión Venecia de 15-16 de junio de 2012, no solo en la forma, sino también en lo que se refiere al espíritu de la Constitución, que no puede ser reformada en su totalidad precisamente en aplicación del propio art. 195 CB (CDL-AD(2012)010). El art. 195 transitorio deroga dos aspectos del procedimiento de reforma de ese mismo precepto al eliminar la disolución del Parlamento y la celebración de nuevas elecciones, para sustituirlo por un Parlamento ya elegido y un quorum y una mayoría agravada de dos tercios de las cámaras. Sobre este punto, cfr. A. Mastromarino, «Modificaciones constitucionales en Bélgica. La sixième réforme de l'Etat: un proceso en marcha», Revista d'EstudisAutonòmics i Federals, n. ${ }^{\circ}$ 22, Octubre, 2015, p. 72. 
presididos por Philippe Moureaux, quienes presentaron un informe al Comité de aplicación de las reformas (COMORI: Comité de mise en xuvre des réformes institutionnelles) integrado por los presidentes de los partidos del acuerdo. Las conclusiones de la Ponencia de estudio del Senado, tuvieron el mérito de aportar un catálogo de cuestiones ligadas a la reforma del Senado y que no habían sido tratadas a fondo en la negociación política, sin dibujar una clara apuesta en cuanto a las opciones barajadas.

Con el nuevo Senado se piensa que por fin se dice adiós al «bicameralismo a la antigua». El anterior modelo había venido manifestando su agotamiento en especial por relación a la evolución de la forma territorial del Estado, pero particularmente por la acusada carencia de linealidad a la que conducía su no correspondencia clara con los paradigmas conocidos de cámaras de representación territorial, al combinarse elementos tan heterogéneos que hacían de la composición de aquel Senado una amalgama de principios antagonistas que hacían urgente una operación de simplificación?. Hasta 1993, el Senado se componía de 184 senadores (106 senadores eran elegidos de forma directa, junto a 52 senadores provinciales y 26 senadores cooptados). La reforma en 1993 redujo considerablemente el tamaño de la cámara, hasta por debajo de la mitad situando su composición en 71 senadores, pero manteniendo la composición híbrida, pues la integraban 40 senadores elegidos directamente ( 25 en la circunscripción neerlandófona y 15 en la francófona), a los que se añadían 21 senadores de las Comunidades lingüísticas (10 de la Comunidad flamenca, 10 de la francesa y uno de la alemana) y diez senadores cooptados (seis designados por senadores neerlandófonos y cuatro francófonos). Pero sobre todo, se introdujo un sistema de escrutinio para los senadores de elección directa que acarreó efectos paradójicos e incluso perversos ${ }^{10}$, al propiciar que los candidatos principales (los tenores de la política nacional) se presentaran al Senado, ya que al ser mayor el tamaño de las circunscripciones en esta cámara, el electorado potencial era mayor, confiriéndoles así una legitimidad democrática que no podían obtener si se presentaban a las elecciones a la Cámara de Representantes ${ }^{11}$, de modo que justo cuando la cámara baja reforzaba su preeminencia respecto al Senado, los principales líderes políticos del país concurrían a las listas de éste.

No han faltado tampoco las posiciones políticas en favor de la supresión del Senado desde hace ya algunos años ${ }^{12}$. El partido Vlaams Belang lleva reclamando

9 Cfr. Y. Lejeune, «L'octroi de compétences nouvelles au Sénat dépend de la composition de cette assemblée fédérale», AA.VV., Quelles réformes pour le Sénat? Propositions de 16 constitutionnalistes, Bruylant, Bruxelles, 2002, p. 56.

10 Cfr. P. Delwit - J-Benoît Pilet, «Fédéralisme, institutions et vie politique. Stabilité, instabilité et retour», M.T. Coenen, S. Govaert, J. Heinen (coords.), L'Etat de la Belgique: 1989-2004: quinze années à la charnière du siècle, Bruxelles, De Boeck \&Larcier, 2004, p. 49.

11 Con más detalle, vid.J.J. Ruiz Ruiz, El veto del Senado, Madrid, CEPC, 2007, p. 391.

12 Ibid., pp. 387 y ss. 
por ejemplo la supresión del Senado desde hace tiempo. Incluso ha habido primeros ministros que han llegado a proponerlo en la Declaración de política general, como la fusión de las dos cámaras en 20013. Durante la legislatura 2010-2014, en la que se ha acometido la última reforma, no han faltado tampoco propuestas en esa misma dirección.

Finalmente, en la reforma constitucional de 1993 se optó por desmantelar el bicameralismo integral; instaurando tres categorías de leyes en función de su necesaria o innecesaria tramitación por el Senado, de modo que se dio entrada a las leyes monocamerales en cuatro supuestos (art. $74 \mathrm{CB})^{14}$, leyes bicamerales obligatorias (art. 77 de la CB), y las leyes bicamerales opcionales (art. $78 \mathrm{CB}$ ). Bajo esta tripartición de las leyes y, en especial con la introducción de las leyes monocamerales, se «vulneraba» el principio bicameral que proclama el art. 26 $\mathrm{CB}$, que prescribe que «el poder legislativo se ejerce colectivamente por el Rey, la Cámara de representantes y el Senado» ${ }^{15}$.

En los denominados Acuerdos de Saint-Michel de 1993, que precedieron a la reforma de aquel año, se pretendió atribuir al Senado un papel de pacificación comunitaria, debido a su composición idónea para resolver los conflictos intercomunitarios, ya que estaba formado en parte, por parlamentarios que habían sido elegidos en un parlamento comunitario y de ahí designados para ser senadores. De hecho, el Senado pasaba a convertirse en la única cámara que permitía acumular el mandato nacional con el de otra cámara, en este caso el cargo de parlamentario en un Consejo de Comunidad (art. 119 CB de 1993). Con anterioridad a esta revisión constitucional de 1993, y desde 1980 en que se crean las regiones, los parlamentos (consejos) regionales y comunitarios se componían de parlamentarios nacionales que podían acumular dos, tres y hasta cuatro mandatos, dando lugar a una suerte de desdoblamiento funcional del Parlamento nacional, que impedía reflejar una representación in proprio de la identidad regional o comunitaria. Por otra parte, la reducción de puestos en el Senado de 184 a 71, y también en la Cámara de Representantes (de 212 a 150), estuvo motivada no por procurar un ahorro presupuestario, sino para evitar la inflación de cargos parlamentarios, al introducir la elección directa para los consejos comunitarios y regionales ${ }^{16}$.

Sin embargo, en la práctica, el Senado no ha desempeñado esa función pacificadora a la que respondía su diseño, a pesar de disponer para ello del procedimiento de conflicto de intereses creado en 1993, previsto en el art. $143 \mathrm{CB}$, que dispo-

13 Cfr. M. Verdussen, «El Senado belga: Pasado, presente y futuro», J.J. SolozÁbal (ed.), Repensar el Senado. Estudios sobre su reforma, Senado, 2008, p. 210.

14 En concreto, quedaban sometidas al procedimiento monocameral las leyes sobre naturalización, las de presupuestos generales del Estado, las relativas a la responsabilidad civil y penal de los ministros y las de fijación de contingente militar.

15 Vid. F. Delpérée, «Le istituzioni», ID. (coord.), L'ordinamento federale belga, Torino, Giappichelli, 1996, p. 205.

16 Cfr. R. ERGec, «Le paysage institutionnel après la quatrième réforme de l'État», Revue Belge de Droit International, 1994/1, p. 18. 
ne que «El Senado se pronuncia por acuerdo motivado sobre los conflictos de intereses entre las asambleas que legislan por medio de ley, decreto o regla del art. 134 de la Constitución». Este procedimiento, desarrollado en el art. 32 de la Ley de 9 de agosto de 1980 sobre reformas institucionales, y que algunos han equiparado al de un conflicto de competencias $^{17}$, tiene lugar bajo dos supuestos: cuando una asamblea legislativa o bien cuando un gobierno consideren que sus intereses pueden ser lesionados gravemente, respectivamente, por un proyecto de legislación depositado ante otra asamblea legislativa, o por un proyecto de decisión (o ausencia de decisión) de otro gobierno. En el caso del conflicto gubernamental, todo órgano gubernamental que se considere gravemente lesionado por una decisión u omisión, puede acudir al Comité de concertación, que dispone de un plazo de sesenta días, para adoptar una decisión según un procedimiento de consenso.Cuando el conflicto de intereses afecte a proyectos o proposiciones de ley estatales, regionales o comunitarios depositados en una asamblea legislativa, o bien a enmiendas introducidas a los mismos por aprobación del Pleno, cualquier otra cámara parlamentaria que se considere gravemente lesionada puede solicitar, mediante moción adoptada por mayoría de $3 / 4$, la suspensión del procedimiento legislativo iniciado en el seno de la otra asamblea ${ }^{18}$. La misión del Comité no es tanto la de zanjar el conflicto de intereses como la de propiciar una negociación. El Comité se compone paritariamente de representantes del Gobierno federal y de los gobiernos federados. Con independencia de que haya o no dictamen del Comité, que no es vinculante, el procedimiento legislativo se reanuda.

A partir de la reforma de 2014 el Senado pasa a estar compuesto por representantes de todas las entidades federadas. Cincuenta senadores de los sesenta que integrarán la nueva cámara ejercen de este modo el mandato de senador de manera paralela a la del mandato de parlamentario de una Comunidad y/o de Región. Existe por tanto la posibilidad de compatibilizar un triple mandato que agrupe el cargo de parlamentario regional, el de parlamentario comunitario y el de senador. Hasta la reforma de 2014, el Senado se hallaba compuesto de 40 senadores de elección directa, 21 senadores designados por los Parlamentos de Comunidad y 10 senadores cooptados, a los que se debía añadir 3 senadores más de derecho (Philippe, Astrid y Laurent de Bélgica, hijos del Rey). Tras la reforma de 2014 los senadores de Comunidad representarán menos de un tercio del Senado, lo cual supone una drástica reducción respecto al Senado previo a la reforma, pero a cambio las entidades federadas tendrán más peso en lo que se refiere a materias institucionales y los derechos y libertades.

En la parte institucional los acuerdos contemplaban una reforma del Senado así como del bicameralismo (en el que entran el funcionamiento y competencias de las

17 Vid. F. Perin - B. Dewez, «Les conflits d'intérêts», Administration publique, 1979-1980, mai 1980 , p. 159.

18 Vid. F. Delpérée - S. Depré, Le système constitutionnel de la Belgique, Bruxelles, Larcier, 2000, p. 257. 
dos cámaras del Parlamento). Asimismo, se incluye en el apartado institucional el reconocimiento de autonomía constitutiva a la región de Bruselas-Capital y a la Comunidad germanófona, mientras que se amplía la autonomía constitutiva de algunas de las entidades federadas para decidir sobre la duración de la legislatura de sus Parlamentos y también sobre la fecha de las elecciones de éstos. Este último extremo plantea la duda de si implícitamente se estaría reconociendo la facultad de disolución anticipada de los respectivos Parlamentos valón, francófono y flamen$\mathrm{co}^{19}$, y si dicha facultad contemplaría la opción de la autodisolución, ciertamente extraña en el parlamentarismo ${ }^{20}$. En cuanto al derecho electoral, se había acordado el principio de simultaneidad de las elecciones federales, regionales y europeas.

\section{LA NUEVA COMPOSICIÓN}

$\mathrm{El}$ art. $67 \mathrm{CB}$, tras su reforma, prevé una composición del Senado que establece dos categorías de senadores: los senadores de las entidades federadas y los senadores cooptados.

La reforma ha supuesto por tanto la supresión de 40 senadores anteriormente elegidos directamente, lo cual significa la reducción más importante que ha tenido lugar en una asamblea representativa en Bélgica. Desde el punto de vista económico supone también una reducción en remuneraciones, no solo ya por la supresión de los 40 escaños, sino porque a partir de ahora el Senado como cámara solo pagará la retribución de los senadores cooptados, — que son solo diez-, a los que además se retribuye con la remuneración de tiempo parcial y no con la de tiempo completo, de manera que los sueldos a tiempo completo de los 40 senadores que se suprimen significará un ahorro en las retribuciones ${ }^{21}$. La reducción del gasto ha estado presente también en los estudios dedicados a calcular el ahorro que conllevaría la supresión del Senado, que lo han cifrado en 59,8 millones de euros al año.

19 Cfr. Q. Peiffer, «Legislature», M. Uyttendaele - M. Verdussen, Dictionnaire de la Sixième réforme de l'État, Bruxelles, Larcier, 2015, p. 519.

20 En principio la ley especial de 8 de agosto de 1980 que enumera las competencias de los gobiernos de las Regiones y Comunidades no contempla el derecho de disolución del ejecutivo, ni tampoco figura entre las materias que según el art. 123.2 CB pueden ser objeto de regulación en ejercicio de la autonomía constitutiva. Aun así autores como Peiffer entienden que podría tener cabida tanto el derecho de autodisolución de los Parlamentos como el derecho de disolución del Ejecutivo acogiéndose no al título competencial de organización del Ejecutivo sino de su funcionamiento y de funcionamiento del Parlamento apoyándose en el art. 71 de la Ley especial de 8 de agosto de 1980. Cfr. Q. Peiffer, «Autonomie constitutive», M. UytTENDAELE - M. VERdussen, Dictionnaire de la Sixième réforme de l'État, op. cit., p. 85.

21 No obstante, al pasar a depender las remuneraciones de todos los senadores, excepto los cooptados, de sus respectivos Parlamentos, se corre el riesgo de incurrir en disparidades significativas en el montante de las remuneraciones a los senadores por parte de las respectivas cámaras por las que han sido elegidos. Cfr. S. Wattier, «Indemnités parlementaires», M. UytTENDAele - M. Verdussen, Dictionnaire de la Sixième réforme de l'État, op. cit., p. 496. 
Las principales novedades en la composición que se derivan de los arts. 67 y $68 \mathrm{CB}$ han tenido por consecuencia i) excluir al Senado de las reglas sobre elección directa; ii) los senadores de comunidad se pasan a denominar «senadores de las entidades federadas»; iii) las reglas sobre cooptación han debido ser adaptadas; iv) la duración de una legislatura pasa a ser de cinco años; v) las elecciones federales y regionales en adelante se celebrarán de manera simultánea si las separan menos de treinta días; vi) el reparto de escaños de senadores se basa en el «sistema D'Hondt» y sobre el principio de «resto mayor»; vii) se define de manera expresa la noción de «formación política» y se la asocia a la noción de «declaración de correspondencia» a efectos del reparto de escaños de senadores de un mismo grupo lingüístico ${ }^{22}$.

El nuevo art. $69 \mathrm{CB}$ ha reducido de 21 a 18 años la edad de elegibilidad al Senado, igualando así la edad de elegibilidad del Senado con la de los Parlamentos de Comunidades y de Región.

Hasta ahora las entidades federadas estaban representadas en el Senado únicamente por un número limitado de senadores de Comunidad. Sin embargo dicha composición no reflejaba la configuración del nuevo Estado federal, que es de carácter asimétrico. Esa asimetría tiene su traducción en que la Región y Comunidad flamencas fusionaron en 1980 sus instituciones (Parlamento, Gobierno y administración), mientras que la Región valona y la Comunidad francesa siguen teniendo instituciones separadas. Bruselas-Capital, por su parte, es una entidad urbana compuesta de 19 municipios que tienen su enclave en un territorio de habla neerlandesa, pero que alberga al $85 \%$ de los francófonos, y tiene un estatuto casi equivalente al de las otras dos Regiones. Además, las comunidades lingüísticas se encuentran representadas por Comisiones comunitarias (francesa, flamenca y común). Existe también la Comunidad germanófona, de tamaño muy reducido, y que se ubica en el territorio de la Región valona.

La explicación de por qué existían solamente senadores de comunidad lingüística y no en cambio senadores de las regiones, residía en que esta era la forma de trasladar que el sistema institucional belga se asentaba sobre las dos comunidades lingüísticas pero no sobre las regiones, modelo que refleja sobre todo la visión de la parte flamenca sobre la naturaleza del Estado federal belga.

\section{El carácter no electivo del nuevo Senado: Nueva cámara de las Regiones frente a la cámara de Comunidades lingüísticas}

Uno de los cambios más trascendentes de esta reforma del Senado viene dado por la desaparición de la elección directa de senadores. Este tipo de elección daba lugar a un curioso fenómeno, como hemos apuntado más arriba, que comportaba 
que los denominados «tenores de la política» se presentasen sistemáticamente en las listas del Senado, al posibilitar el tipo de circunscripción senatorial una suerte de «plebiscito» en el seno de la respectiva comunidad lingüística ${ }^{23}$. El motivo era que, para la elección de los 40 senadores ahora suprimidos con la reforma, no había más que un colegio electoral neerlandés y un colegio electoral francófono distribuido en tres circunscripciones electorales (la flamenca, la valona y la de Bruxelles-Hal-Vilvorde). Toda la campaña electoral se centraba en los debates de estos candidatos al Senado, líderes de sus respectivos partidos. Sin embargo, tras las elecciones, la atención volvía a estar en la Cámara de representantes que es la que realmente concentra el poder de investir al Gobierno («government making power») y las competencias presupuestarias.

La principal consecuencia de que se hayan derogado las disposiciones sobre la elección directa del Senado es que queda derogado también el enunciado que contemplaba la renovación completa del Senado cada cuatro años, ya que la cámara a partir de ahora se renovará periódicamente de manera parcial, salvo en los supuestos de elecciones simultáneas (art. $117 \mathrm{CB}$ ), de disolución en virtud del art. 195 CB (disolución anticipada por declaración de reforma constitucional) o salvo el supuesto de renovación completa de la cámara de acuerdo con el art. 95 CB (provisión de la vacante al Trono tras disolución de ambas cámaras). Se ha derogado también la regla que establecía que las elecciones de los senadores elegidos directamente tenía lugar el mismo día que las elecciones para la Cámara de representantes.

Habrá en cambio diez senadores que no acumularán un doble mandato o «doublecasquette», en expresión habitualmente empleada por la doctrina. La cámara remunerará únicamente a estos diez senadores ${ }^{24}$.

Se han suprimido asimismo los senadores de derecho mediante la derogación del art. $72 \mathrm{CB}$, que establecía que los hijos del Rey eran senadores de pleno derecho a la edad de 18 años. La derogación no entró en vigor, sin embargo, hasta las elecciones para renovar los Parlamentos de Comunidad y de regiones en 2014.

De acuerdo con el art. 68 CB, una ley especial (de mayoría reforzada) determina las circunscripciones territoriales que se tendrán en cuenta para el reparto de escaños de los grupos lingüísticos respectivos. El reparto de escaños de los senadores de las entidades federadas tendrá lugar en una sola vuelta mediante un sistema de representación proporcional sobre la base del resultado obtenido por una formación política en las elecciones para el Parlamento de comu-

23 A partir de ahora esta posibilidad de acumular el voto de toda una comunidad lingüística solo será posible en las elecciones europeas, de manera que el efecto «aplaudímetro» desaparece de la escena electoral, por lo que no será posible que los primeros ministros busquen mayor legitimidad en el número de votos que arrastra su candidatura.

24 La remuneración se enmarca en la más generalización reducción de remuneraciones impulsada por la 6. ${ }^{a}$ reforma del Estado. Para una panorámica general de la desaparición de remuneraciones, cfr. J. FANIEL, «Indemnités parlementaires: une réforme forcé et inégale», Le Crisp en ligne, 15 décembre 2011, p. 12 
nidad o de región respectiva. El sistema proporcional escogido se remitía a una ley posterior ${ }^{25}$.

Ahora bien, si la regla del art. 68 CB parece clara, su combinación con la barrera electoral establecida por el art. 210 decies del Código electoral ${ }^{26}$ plantea alguna duda en cuanto a su interpretación respecto al reparto de escaños. En efecto, si bien el art. 68 CB dispone que los escaños en el Senado se reparten entre las listas «según la suma de los votos obtenidos por cada una de ellas en las diferentes circunscripciones electorales en las elecciones al Parlamento de la Región valona y los votos obtenidos por las listas del grupo lingüístico francés en las elecciones al Parlamento de la Región Bruselas-Capital», siguiendo un sistema de representación proporcional determinado por la ley, por su parte el nuevo art. $210 \S 2$ del Código electoral ha previsto en cuanto a la barrera electoral que: «Solo se admiten al reparto de escaños las formaciones políticas cuyas listas hayan obtenido al menos el $5 \%$ del total general de votos válidamente emitidos en la elección tanto del Parlamento valón como del grupo lingüístico francés del Parlamento de la Región de Bruselas-Capital».

A pesar de que la dicción de este precepto del Código electoral no ha empleado términos como «a la vez» o «en cada una de las elecciones», que inequívocamente habrían exigido un cómputo separado de ese umbral del $5 \%$, se ha interpretado por una de las formaciones políticas que han concurrido a las primeras elecciones senatoriales tras la reforma constitucional como un único umbral del $5 \%$ de votos computables tanto las elecciones a ambos Parlamentos (valón y bruselense) a la vez. Sin embargo, el servicio jurídico del Senado ha aplicado en estas primeras elecciones una interpretación consistente en aplicar un doble umbral, por el que toda formación política debería obtener más de un $5 \%$ en Valonia y en Bruselas, pero de modo separado ${ }^{27}$. Resulta sin embargo llamativo que en su Nota interpretativa, el servicio jurídico del Senado admita que la interpretación literal conduce a aplicar la barrera electoral de manera conjunta a ambas elecciones, pero que se trata de un error de redacción manifiesto ${ }^{28}$. Sin embargo, esta interpretación parece estar en contradicción con la Constitución, cuyo art. 68.1 (párrafos tercero a quinto) en su redacción tras la reforma de 6 de enero de 2014, exige que los escaños del Senado designados por los parlamentos se repartirán entre las listas según la adición de votos obtenidos en las diferentes circunscripciones electorales para el Parlamento de la Región valona y la adición de votos de las listas para el grupo lingüístico francés, obtenidos en las elecciones para el Parlamento de la Región de Bruselas-Capital ${ }^{29}$.

25 Loi du 6 janvier 2014 modifiant le Code électoral suite à la réforme du Sénat, Moniteur Belge 31 janvier 2014 .

26 Introducido por la Ley de 6 de enero de 2014, Loi de modification du Code électoral suite à la réforme du Sénat.

$27 \mathrm{Vid}$. Note rédigée par le service juridique du Sénat relative à la procédure pour le renouvellement du Sénat, p. 8.

28 Ibid., p. 8, nota a pie n. 34.

29 El Partido del Trabajo de Bélgica (PTB) interpuso, invocando esta interpretación, un recurso ante el Consejo de Estado, al no haber obtenido escaño senatorial a pesar de haber superado ligeramente en las elecciones de 25 de mayo de 2014 el 5\% de votos (5,44\%), sumando el voto en las elecciones al Parlamento valón y 
La exigencia impuesta por el art. 68.1 CB, párrafo cuarto, de contar con al menos un escaño tanto en la elección del Parlamento valón como en los Parlamentos de la región Bruselas-Capital y el Parlamento de la Comunidad francesa, conjuntamente con la barrera electoral del 5\% aplicable tanto en la elección del Parlamento valón como en la del grupo lingüístico francés del Parlamento de la región Bruselas-Capital, restringen las posibilidades de obtener un escaño en el Senado para los pequeños partidos francófonos (con las consiguientes implicaciones financieras $)^{30}$, dificultad que no se presenta del lado neerlandés, pues en su momento se optó por la fusión de sus instituciones regionales y comunitarias ${ }^{31}$. Como ha observado Verdussen, se produce así un desvío de escaños en provecho de partidos políticos francófonos que tengan implantación nacional ${ }^{32}$.

El reparto de los escaños de los 29 senadores que forman parte del grupo lingüístico neerlandés del Senado se designan por el Parlamento flamenco basándose en el resultado de las elecciones a dicho Parlamento. Las cifras electorales de todas las listas de una misma formación se adicionan de modo que el reparto entre formaciones tiene lugar mediante el sistema D'Hondt ${ }^{33}$.

Para los 20 senadores de las entidades federadas que pertenecen al grupo lingüístico francés del Senado, de entre los cuales 10 se designarán por el Parlamento de la Comunidad francesa, 8 por el Parlamento de la Región valona y 2 por el grupo lingüístico francés del Parlamento de la Región Bruselas-Capital, la atribución de escaños se basa en el resultado de las elecciones para el Parlamento de la Región valona y para el grupo lingüístico francés, según los votos a las elecciones del Parlamento de la Región de Bruselas-Capital. Tres de los senadores designados por el Parlamento de la Comunidad francesa proceden del grupo lingüístico francés del Parlamento de la Región de Bruselas-Capital. Por tanto de los veinte senadores francófonos, diez se designan por el Parlamento de la Comunidad francesa y diez por los Parlamentos regionales (8 el valón y 2 el bruselense). Se produce por tanto un equilibrio entre la designación por el Parlamento de la

al de Bruselas-Capital. El Consejo de Estado en su arrêt n. ${ }^{\circ} 227.788$, de 20 de junio de 2014, se declaró incompetente al entender que el recurso afecta a la verificación de poderes por el Senado prevista en el art. 48 CB.

30 La no obtención de un escaño en el Senado en efecto reduce considerablemente la financiación de un partido político. Cfr. C. SÄGesser, C. Istasse, Le Sénat et ses réformes successives, Courrier hebdomadaire du CRISP, n. ${ }^{\circ} 2219-2220,2014$, p. 61.

31 En efecto, la Comunidad flamenca, en uso del art. 137 de la anterior Constitución decidía asumir las competencias reconocidas a la Región, mediante el art. 1 de la ley especial de 8 de agosto 1980 de reformas institucionales, creando de ese modo una asimetría institucional respecto a la Región valona y la comunidad francesa. Sin embargo en realidad no se trata de una fusión entre Comunidad y Región, ya que ambas no abarcan el mismo territorio, de manera que mientras que Bruselas forma parte de la Comunidad flamenca, no integra en cambio el territorio de la Región flamenca, de la que no forma parte. De ahí que los diputados bruselenses en el Parlamento flamenco no tengan derecho de voto en materias regionales. Cfr. M. GoossEns, Le parlement flamand, Bruxelles, Lannoo, 2003, p. 34

32 Vid. M. Verdussen, «La dernière réforme du Sénat de Belgique», Revistacatalana de dretpúblic, n. ${ }^{\circ}$ 51, (décembre 2015), p. 81.

33 Art. 210 octies del Código electoral (introducido por la Ley 2014-01-06/58, de 6 de enero). 
Comunidad francesa y la designación por los Parlamentos regionales (valón y bruselense), dando acogida a la fórmula 10/10. Así pues, las cifras electorales resultantes de la suma de votos de todas las listas para las dos elecciones (comunitaria francesa y regional valona o bruselense) que pertenezcan a una misma formación política son sumadas entre sí. El reparto de escaños entre formaciones políticas se hará de acuerdo al sistema D'Hondt ${ }^{34}$.

Para determinar qué listas pertenecen a una misma formación política, las listas para, por un lado el Parlamento flamenco, y por otro lado para la elección del Parlamento de la Región valona y las listas para la elección del grupo lingüístico francés del Parlamento de la Región Bruselas-Capital deben presentar una declaración de correspondencia (art. 210 quinquies del Código electoral). El objetivo de dicha declaración de correspondencia es el de organizar el reparto de escaños a las listas que se presentan en distintas circunscripciones electorales. Por ello no serán válidas las declaraciones de correspondencia de listas de una misma circunscripción electoral. Si una de las listas que figure en la declaración fuera rechazada, ésta última seguirá siendo válida para las demás listas del grupo lingüístico en cuestión. Por último, el Parlamento de la Comunidad germanófona designa a su vez solo un senador de entre sus miembros, por lo que no depende de una elección.

Para poder ser tenido en cuenta para la atribución de escaños, toda formación política debe haber obtenido un $5 \%$ del total general de los votos válidamente emitidos para cada una de las elecciones sobre la que se efectúa la atribución de escaños. La originalidad del sistema reside en que una lista no será tenida en cuenta para el reparto de escaños nada más que para un solo grupo lingüístico ${ }^{35}$.

Es conveniente precisar que, tanto en la Cámara de Representantes como en el Senado, el reparto en grupos lingüísticos no impide que un grupo político pueda contar con miembros de dos grupos lingüísticos. El art. 67. 1 CB, enumera el origen de los miembros del nuevo Senado, pero en su párrafo 2 introduce una restricción respecto a los diez senadores que debe elegir el Parlamento de la Comunidad francesa de entre sus miembros, al exigir que tres de los senadores designados deben pertenecer al grupo lingüístico francés del Parlamento de Bruselas-Capital. Respecto a los tres senadores del Parlamento de Bruselas-Capital, la disposición del art. 67.2 CB no precisa si deben ser miembros del Parlamento de la Comunidad francesa o no, especificando que en uno de los nombramientos no es necesario que el Senador pertenezca al Parlamento de la Comunidad francesa, pero sin que exista obligación para los otros dos de que sea así. El Parlamento

34 Art. 210 octies del Código electoral (introducido por la Ley 2014-01-06/58, de 6 de enero).

35 La división de escaños en grupos lingüísticos es un reflejo de la división lingüística de las circunscripciones electorales y de la representación de cada ente federado (a excepción de Bruselas), sistema que se introdujo por primera vez para las primeras elecciones europeas en 1979 y para el Senado en 1995, y que divide el país en zonas lingüísticas. Tras la reforma de 2014, el art. 43.2 CB divide el Senado en dos grupos, francófono y neerlandés (a excepción del senador de la comunidad alemana). 
de la Comunidad francesa puede por tanto designar, entre el grupo francófono del Parlamento bruselense, un senador que no sea a su vez miembro del Parlamento de la Comunidad Francesa ${ }^{36}$.

Tras la reforma del Senado, todos los miembros de Parlamentos de comunidad o de región, incluidos los senadores designados por ellos, serán retribuidos por su cargo de parlamentario de esos Parlamentos de los que son miembros. No obstante, en cuanto a la retribución se establece una distinción entre el senador designado por el Parlamento de la Comunidad germanófona (art. 67.1, párrafo 5) y los otros senadores. Hasta ahora, la retribución de senadores y de miembros de la Cámara de representantes se encontraba fijada en la Constitución, siendo el triple la retribución de estos últimos respecto a la percibida por los senadores. Estos artículos de la anterior Constitución habían caído en desuso. Incluso en su origen los senadores no tenían derecho a ninguna retribución ${ }^{37}$. En efecto, en la creación del Parlamento belga los senadores no percibían retribución alguna, sino una dieta, ya que en sus orígenes los senadores eran personas de una condición social muy elevada ${ }^{38}$. La retribución de los senadores se ha venido estableciendo posteriormente por vía reglamentaria hasta la actual reforma constitucional. Con la reforma constitucional de 2014 los senadores de los entes federados pasan por tanto a ser retribuidos por los parlamentos de los que son miembros. Y en cuanto a los senadores cooptados, es el Senado el que les retribuye con una cantidad establecida en el Reglamento de la cámara.

Otra novedad que afecta a la composición del Senado es que a partir de ahora no podrá albergar más de dos tercios de senadores del mismo género en virtud del art. 67.3 CB, por lo que según el Consejo de Estado, los senadores de los entes federados que se encargan de la designación de los senadores cooptados, deberán de ponerse de acuerdo a fin de respetar esta regla del art. 67.3 CB. De momento, sin embargo, el incumplimiento de esta obligación de designar al menos $1 / 3$ de senadoras, no lleva aparentemente asociada una sanción, como no sea la de la

36 Los Parlamentos valón, flamenco, el de la Comunidad francesa y el de la Comunidad germanófona designan cada uno en su seno senadores. En cambio no ocurre así con el Parlamento de la Región de Bruselas-Capital. Únicamente es el grupo lingüístico francés en ese parlamento el que designa de entre sus miembros 2 senadores. Esta supuesta marginación de una representación del Parlamento de Bruselas-Capital a título propio ha sido el blanco de las críticas de la coalición de partidos de PS/Open, VLD/FDF/SP.A/, CDH/ $\mathrm{CD} \& \mathrm{~V}$, que ya han reivindicado esta corrección para la siguiente reforma del Senado. Cfr. CÉDRIC IsTASSE, «Quel devenir pour le nouveau Sénat? Premier bilan», Les Analyses du Crisp en ligne, 21 Mai 2015, p. 10.

37 Estimaba uno de los más conocidos comentaristas de la Constitución de 1831 que para los grandes propietarios que iban a componer el Senado, el sacrificio de una estancia en la capital quedaba compensado con la dignidad de la que habían sido investidos por el sufragio de sus conciudadanos. Vid. J.-J. ThONISSEN, Constitution belge annotée, Hasselt, P.-F. Milis, 1844, p. 177.

38 En efecto, esta prohibición de remuneración o dieta se encontraba en el art. 57 de la Constitución de 1831, y perdura hasta la revisión constitucional de 1921 en la que se reforma el art. 57 CB que determina que les «sénateurs ne reçoivent pas de traitement. Ils ont droit, toutefois, à être indemnisés de leurs débours; cette indemnité est fixée à quatre mille francs par an». Cfr. J. FANIEL, «La rémunération des parlementaires et des ministres», Courrier hebdomadaire du CRISP 2009/9 (n. $\left.{ }^{\circ} 2014-2015\right)$, p. 10. 
anulación por inconstitucionales de los actos de designación. La imposición, por otra parte, de esta cuota solo para el Senado, ha sido vista como una suerte de premio de consolación para una efectiva paridad, dotando de un mínimo de representación femenina la asamblea «más insignificante de todo el país» ${ }^{39}$.

\section{La designación de senadores cooptados}

Los senadores de los entes federados deben designar diez senadores cooptados. La atribución de escaños se realizará sobre los resultados de las elecciones a la Cámara de representantes, siguiendo el sistema de representación proporcional contemplado en el art. 63.2 CB. Esta fórmula, que comporta un vínculo entre la elección de senadores y la elección a la Cámara de Representantes, explicable por el deseo de los partidos reformadores de dar un toque federal a la composición del Senado $^{40}$, no se encuentra desde luego muy en sintonía con la filosofía de esta reforma, que pretendía hacer del Senado una cámara de los entes federados ${ }^{41}$, en especial si se tiene en cuenta que esos senadores cooptados lo son en representación de cada grupo lingüístico, lo cual podía tener sentido con un Senado como el que se deja atrás, de senadores de elección directa y de las comunidades lingüísticas en proporción a los resultados de las elecciones senatoriales.

Entre estos senadores cooptados, 6 formarán parte del grupo lingüístico neerlandés del Senado y 4 serán miembros del grupo lingüístico francés del Senado. Como ya se ha apuntado, la atribución de los escaños de los 10 senadores cooptados se lleva a cabo sobre la base del número de votos total obtenido por cada formación política en las elecciones a la Cámara de Representantes.

La atribución de escaños por grupos lingüísticos del Senado se encuentra en cambio exigida por la Constitución (en el caso de los senadores cooptados, 6 escaños para el grupo neerlandés y 4 para el grupo francófono). Precisamente este reparto de escaños es uno de los asuntos que más han avivado los conflictos comunitarios a lo largo de las últimas décadas. Las largas y difíciles negociaciones para la formación de un Gobierno entre 2007 y 2010 tuvieron como uno de sus obstáculos el respeto a la división del país en regiones lingüísticas, y en especial se manifestó en toda su intensidad en el rediseño de la circunscripción de Bruxelles-Hal-Vilvorde, un problema de tal magnitud que es conocido como «la corona de espinas del Estado Federal belga» ${ }^{42}$. La reforma legal relativa a la escisión de dicha circunscripción (ley de 19 de julio de 2012, que modificaba el art. 87

39 La opinión es de C. Behrendt, Vid. «Le Sénat après les élections: un nouveau «brol» belge», L'Avenir, 13 Mai, 2014.

40 Vid. A. FEYT, «La réforme du Sénat, un tableau inachevé...», en p. 89.

41 Doc. Parl., Sénat, 2011-2012, n. ${ }^{\circ}$ 5-1525/1, p. 2.

42 Vid. B. Blero, «Bruxelles-Hal-Vilvorde, couronne d'épines de 1'État fédéral belge?», Pouvoirs, n. ${ }^{\circ} 136$, p. 97. 
del Código electoral), fue sometida al dictamen del Consejo de Estado, que no la consideró contraria al principio de igualdad y al de no discriminación (arts. 10 y $11 \mathrm{CB})^{43}$, invocando al respecto la jurisprudencia del Tribunal europeo de Derechos humanos ${ }^{44}$, y la del propio Tribunal Constitucional, que admite ciertas limitaciones a derechos fundamentales o un diferente trato cuando de modo razonable se pueden considerar medidas de este tipo no desproporcionadas respecto al objetivo de salvaguardar un interés público superior por parte del legislador, en este caso la preservación de un consenso comunitario que garantiza los grandes equilibrios sobre los que se construye la paz comunitaria ${ }^{45}$.

La atribución de escaños de los senadores cooptados se lleva a cabo mediante el sistema electoral de «resto mayor» (art. 68.2 CB). Se ha remitido a una ley especial el detalle del método de cálculo y la determinación de las circunscripciones que se toman en cuenta para la atribución de escaños a los senadores cooptados de cada grupo lingüístico (neerlandés y francés).

La opción de designar los 10 senadores cooptados sobre la base del resultado de las elecciones a la Cámara de Representantes no ha estado exenta de críticas, puesto que parecía más lógico haber realizado ese cálculo sobre el número de votos obtenidos en las elecciones para los parlamentos de los entes federados. La designación de senadores cooptados se lleva a cabo por los senadores de los entes federados nombrados al objeto por los miembros de la Cámara de Representantes pertenecientes a la formación a la que se hayan atribuido los escaños. Las formaciones políticas de cada grupo lingüístico del Senado proceden a la designación de tantos candidatos como senadores cooptados le correspondan.

\section{Incompatibilidades de los nuevos senadores}

El art. $119 \mathrm{CB}$ establece una incompatibilidad entre, por una parte, el cargo de miembro de un Parlamento de Región o de Comunidad, y por otra, el mandato de miembro de la Cámara de Representantes o de senador cooptado previsto en el art. $67, \S 1,6 .^{\circ}$ y $7 .^{\circ} \mathrm{CB}^{46}$. No se da opción a escoger cargo, sino que el jura-

43 Se debe precisar no obstante que el Consejo de Estado se pronunció sobre una proposición de ley, que actuaba una reforma constitucional que, si bien era previsible, se encontraba todavía en tramitación. La posibilidad, por otra parte, de introducir un trato diferenciado para ciertas circunscripciones, había sido ya admitida por el Tribunal Constitucional (entonces Tribunal de Arbitraje) en su Sentencia n. ${ }^{\circ} 73 / 2003$, en la que encomendaba al legislador dicha tarea. Cfr. Avis du Conseil d'État no 51.214/AG du 2 mai 2012, Doc. parl., Sénat, 2011-2012, no 1560/2, pp. 6 y 7.

44 Vid. Sentencia TEDH, Mathieu-Mobin et Clerfayt c. Belgique (2 de marzo de 1987).

45 Cfr. Sentencias del TC, n. ${ }^{\circ} 18 / 90$, de 23 de mayo de 1990 , FJ. B.9.2; n. ${ }^{\circ} 35 / 2003$, de 25 de marzo de 2003, FJ. B.13.3., n. ${ }^{\circ}$ 18/90, de 23 de mayo de 1990, FJ. B.9.2, n. ${ }^{\circ} 18 / 90,23$ de mayo de 1990, B.9.2.

46 Sénat, Documents: 5-1730, Annales du Sénat: 26 et 28 novembre 2013. Vid. también art. 233.2 del Código electoral. 
mento como diputado regional o comunitario causa la pérdida automática de su condición de senador cooptado.

Mayor relevancia tiene la desaparición de la anterior incompatibilidad entre ser miembro de un Parlamento de comunidad o de región con el cargo de senador elegido directamente o el cargo de senador de la Comunidad germanófona (anterior art. 24bis de la ley especial de reformas institucionales de 8 de agosto de 1980). De hecho, la Constitución parece privilegiar la posibilidad de simultanear el cargo de parlamentario comunitario y regional lo que, sumado a la condición de senadores designados en el seno de dichos Parlamentos, puede dar lugar a situaciones de triple mandato (diputado comunitario, regional y senador $)^{47}$. La excepción, ya apuntada, es la de los senadores cooptados, que no pueden simultanear su cargo con el de parlamentario regional o comunitario ${ }^{48}$. Por lo demás no se puede simultanear la condición de diputado del Parlamento de la Comunidad francófona, del Parlamento flamenco o del Parlamento de la Comunidad germanófona ${ }^{49}$, según el criterio de que no se puede ser a la vez parlamentario de una región o comunidad de habla distinta, resultando plenamente compatible en cambio cuando los cargos parlamentarios se corresponden con los de una misma comunidad lingüística, hasta el punto de que los 75 diputados del Parlamento valón son miembros de pleno derecho del Parlamento de la Comunidad francesa ${ }^{50}$.

En cambio, se aplica a todas las categorías de senadores, cooptados o no, la incompatibilidad de senador con el cargo de ministro del Ejecutivo federal, regional o comunitario, o Secretario de Estado también federal, regional o comunitario. En efecto, por lo que se refiere en primer lugar a los senadores cooptados, el art. 233.2, párrafo tercero del Código electoral, impone la pérdida de pleno derecho automática de su mandato senatorial por el nombramiento o designación como ministro o secretario de Estado federal o ministro regional o comunitario. En cuanto a los senadores de parlamentos regionales y comunitarios, que es el grupo de senadores más numeroso (50 de 60), el art. 24 §2bis de la Ley de 8 de agosto de 1980, estipula que «el miembro del Parlamento de la Comunidad francesa, del Parlamento valón, o del Parlamento flamenco, nombrado por el Rey en calidad de ministro o de secretario de Estado federal y que acepte, cesa inmediatamente en sus funciones», funciones que no obstante retomará cuando se produzca el cese en su puesto de Ministro o de Secretario de Estado. No se trata por tanto estrictamente de una causa de incompatibilidad, sino de una prohibición de acumulación de mandatos. Esta misma causa de incompatibilidad se ha introducido para los miembros del Parlamento de Bru-

47 Cfr. M. Uyttendaele, Les institutions de la Belgique, Bruxelles, Larcier, 2014, p. 172.

48 Vid. art. 233.3 del Código electoral.

49 Vid. Art. 24 bis $\$ 4$ de la Ley especial de 8 de agosto de 1980, de reformas institucionales.

50 Art. $24 \$ 3$ de la Ley especial de 9 de agosto de 1980 sobre reformas institucionales. 
selas-Capital en $2012^{51}$, por lo que, desde las elecciones de 2014, la condición de parlamentario bruselense se pierde de pleno derecho al ser nombrado ministro federal, regional o comunitario, resultando así una incompatibilidad absoluta. En cuanto a los ejecutivos regionales y comunitarios, todas las entidades federadas han hecho uso de la facultad que les reconoce el $49, \S 2$, de la ley especial de 8 agosto de 1980, de establecer por decreto (nomen iuris de la ley regional o comunitaria, art. $134 \mathrm{CB}$ ) el cese automático de los respectivos parlamentarios cuando sean nombrados miembros de sus respectivos gobiernos ${ }^{52}$. Así pues, tanto la regulación de Flandes, como las de la región de Valonia y de la Comunidad francesa imposibilitan el nombramiento de senadores que puedan compatibilizar su condición de parlamentarios y de miembros del Ejecutivo, cerrando así toda posibilidad de aproximar la composición del Senado a la del modelo del Bundesrat alemán.

Los senadores comunitarios y regionales no pueden tampoco compatibilizar su mandato senatorial con los cargos de alcalde (bourgmestre), concejal (échevin) o presidente de un centro público de ayuda social ${ }^{53}$. Con anterioridad solo se veían afectados por esta incompatibilidad los senadores comunitarios; mientras que ahora se aplica a todos los senadores (regionales y comunitarios) a excepción de los senadores cooptados. Existe controversia sobre si se trata de una incompatibilidad absoluta de cargos o solo de ejercicio para los senadores, de manera que deban dimitir de uno de los dos cargos. Amparándose en la literalidad del art. 1 ter de la ley de incompatibilidades, se viene interpretando por el Senado que la prohibición se refiere al ejercicio del cargo de senador con el de alcalde o concejal, pero al no mencionarse una prohibición de acumulación de mandatos (cumul de mandats), tras haberse constituido el nuevo Senado reformado en julio de 2014, los senadores afectados por esta incompatibilidad han incurrido en la asentada práctica consistente en declararse impedido (empêchê) para ejercer el cargo local, pero sin que ello implique la dimisión, de modo que, sin dimitir de una alcaldía o concejalía, han sido sustituidos por otros concejales (suplentes de lista) mientras dure el mandato de senador.

A su vez, y por exigencia de la desaparición de los senadores electivos, ha sido necesario suprimir la incompatibilidad de la remuneración como miembro de un Parlamento comunitario o regional y la remuneración de senador (del anterior art. 31 ter $1{ }^{\circ}$ de la ley especial de reformas institucionales de 8 de agosto de 1980), puesto que su remuneración ya no correrá a cargo del Senado, sino del respectivo Parlamento del que son miembros.

51 Cfr. art. 5 de la Ley de 19 de julio de 2012, de modificación de la legislación electoral para el refuerzo de la democracia y de la credibilidad política, que introdujo el art. 12 bis en la Ley especial de 12 de enero de 1989 relativa a las Instituciones bruselenses.

52 Cfr. Décret flamand de 26 de junio de 1995; Décret wallon de 13 de julio de 1995; Décret Communauté française de 24 de julio de 1995, art. 1 bis de la Ley 6 de agosto de 1931 (modificada en 2014).

53 Nuevo art. 1 ter de la Ley de 6 de enero de 2014, de modificación de la Ley de 6 de agosto de 1931, de incompatibilidades y prohibiciones relativas a ministros, antiguos ministros y ministros de Estado, así como miembros y antiguos miembros de las Cámaras legislativas. 


\section{LA PÉRDIDA DE COMPETENCIAS LEGISLATIVAS}

El dictado del art. $36 \mathrm{CB}$, sigue enunciando que «el poder legislativo federal se ejerce colectivamente por el Rey, la Cámara de Representantes y el Senado», sin embargo el propio texto constitucional consagra una derogación parcial de dicho enunciado en su art. 74, que expresamente dispone que «por derogación expresa del artículo 36, el poder legislativo federal se ejerce colectivamente por el Rey y la Cámara de Representantes en las materias distintas a las contempladas en los artículos 77 y 78». De este modo, se supera la contradicción que suponía mantener el art. $36 \mathrm{CB}$ antes de la reforma de 2014, cuando habiendo introducido ya en 1993 leyes monocamerales para determinadas materias en el anterior art. $74 \mathrm{CB}$, de facto el enunciado del art. $36 \mathrm{CB}$ era parcialmente inexacto. Pero, al mismo tiempo, al excluir al Senado del procedimiento legislativo sobre materias que no sean las expresamente mencionadas en los arts. 77 y $78 \mathrm{CB}$, la reforma ha creado una potestad legislativa residual para la Cámara de Representantes, haciendo del monocameralismo la regla general y del bicameralismo la excepción, cambio muy significativo frente a los cuatro supuestos tasados de la anterior redacción del art. $74 \mathrm{CB}^{54}$.

No se han modificado en cambio los tres tipos de procedimientos legislativos que existían con anterioridad a la reforma del Senado, por tanto siguen subsistiendo el procedimiento legislativo para materias sometidas a un bicameralismo estricto, el procedimiento legislativo para materias sometidas a un bicameralismo opcional y el procedimiento monocameral para el resto de materias. La calificación de los textos legislativos recae, en primera instancia tal y como precisaba el Consejo de Estado en $1995^{55}$, sobre el autor de los mismos, pero corresponde en segunda instancia apreciar la conformidad de la materia del texto con el procedimiento legislativo por el que se pretende tramitar, a la Comisión parlamentaria de concertación, quien puede inadmitir el texto, entrañando entonces la preclusión del procedimiento ${ }^{56}$.

\section{Materias reservadas al procedimiento de bicameralismo obligatorio}

Las competencias federales del Senado se han reducido de manera drástica tras la reforma de los arts. 77 y 78 de la Constitución y especialmente tras las transferencias de competencias a los entes federados. Ahora, y tras la reforma, las

54 Vid. A. Feyt — P. VANDERnACht, «La réforme du Sénat, un tableau inachevé...», J. Sautois, M. UytTENDAEle (dirs.), La sixième réforme de l'État (2012-2013): Tournant historique ou soubresaut, ordinaire?, Limal, Anthemis, 2013, p. 92.

55 Avis du 10 octobre 1995.

56 Cfr. F. Delpérée, «Les principes de la révision constitutionnelle de 1993», A. Leton (coord.), La Belgique: un État Fédéral en évolution, Bruxelles-Paris,Bruylant-LGDJ, 2001, p. 47. 
materias que quedan sometidas a un procedimiento bicameral obligatorio han sido adaptadas, ya que para algunas materias que hasta ahora pertenecían al bicameralismo obligatorio, la Cámara de Representantes y el Senado siguen estando en pie de igualdad, pero otras materias que hasta ahora pertenecían a ese conjunto de materias pasan a formar parte del procedimiento bicameral opcional, mientras que se amplía el grupo de materias que estarán adscritas a un procedimiento exclusivamente monocameral.

Para determinar el procedimiento legislativo aplicable para cada materia, se deberá decidir si una materia es encuadrable entre las enumeradas por el art. 77 CB o si pertenece a las contenidas en el art. 78 CB, de manera que se aplica una suerte de «regla en cascada» para calificar todo proyecto o proposición de ley ${ }^{57}$. Si alguna materia no puede ser encuadrada entre las que comprenden ambos preceptos, el procedimiento aplicable es entonces el monocameral, pero no se debe perder de vista que en la práctica numerosos proyectos o proposiciones de ley son calificados como «mixtos» por sus autores, lo que implica una división o un troceado en su tramitación ${ }^{58}$.

Como materias sometidas necesariamente a procedimiento bicameral han permanecido la declaración de reforma constitucional así como la aprobación de la reforma propiamente dicha (art. 77.1. ${ }^{\circ} \mathrm{CB}$ ), las materias que la propia Constitución señala a lo largo de su articulado, entre las que figuran las disposiciones relativas a la Monarquía que exigen aprobación de ambas cámaras en los supuestos de exención de la pérdida de derechos sucesorios de un heredero al Trono, aceptación por el Rey de la Jefatura de otro Estado, y los supuestos de tutela del Rey menor o nombramiento de un/a Regente por incapacidad del Rey o la provisión del Trono vacante (arts. 85.3, 86.1, 87, 90, 91, 92, 93, 94 y 95 CB), las relativas a libertades y derechos fundamentales, las de reforma del Estado y las de organización institucional del Estado o de los Parlamentos de comunidad (art. 77.2 CB) y las leyes de mayoría especial del art. $4 \mathrm{CB}$ (art. 77.3. ${ }^{\circ} \mathrm{CB}$ ), que exigen para su aprobación mayoría simple dentro de cada grupo lingüístico en cada cámara y mayoría de dos tercios del conjunto de los votos emitidos en cada una de las cámaras. Las materias reservadas a leyes especiales con anterioridad se mantienen en su totalidad. En particular, siguen estando comprendidas dentro de esta categoría: i) las condiciones de mayoría suplementaria exigidas para la adopción de las modalidades de organización de una consulta popular por la Región de Bruselas-Capital, ii) la supresión de las instituciones provinciales ${ }^{59}$, iii) la

57 Vid. C. Fornoville, «De Vlinder-Senaat», op. cit., p. 47.

58 Cfr. D. Eatselé, Initiation à la rédaction des textes législatifs réglementaires et administratifs, 8e édition, Bruxelles, Bruylant, 2013, p. 66.

59 La Sexta reforma del Estado no ha llegado a suprimir las provincias, pero del nuevo marco constitucional resultante de los arts. 41 y 162 CB, así como del marco legal del art. 6.1, VIII de la ley especial de reformas institucionales de 8 de agosto de 1980, se desprende que dicha supresión puede ser acordada por las regiones mediante decreto especial (decreto es el nomen iuris de las leyes regionales en Bélgica) siempre y cuando lo 
atribución a los entes federados de la competencia de regular la duración de su legislatura y iv) la de fijar la convocatoria de elecciones del Parlamento de las entidades federadas con la salvedad de la Comunidad germanófona. Este ámbito material se ha ampliado con la reforma constitucional de 19 de julio de 2012 a tres nuevos bloques de materias: i) la modificación de las reglas que garantizan los intereses legítimos de los neerlandófonos y de los francófonos en la antigua provincia de Brabante; ii) la modificación de reglas sobre el uso de lenguas en materia judicial en el distrito judicial de Bruselas, así como los aspectos relacionados con la fiscalía, su sede y su jurisdicción; iii) la modificación de la competencia de la asamblea general de la sección contencioso-administrativa del Consejo de Estado respecto de seis municipios cercanos a Bruselas para que los justiciables puedan solicitar que sus causas sean sometidas a una jurisdicción paritaria desde el punto de vista de la lengua.

Se incluye otro grupo, en este caso de leyes ordinarias, muy tasadas, que quedan sometidas al procedimiento bicameral obligatorio. En concreto, están sujetas al bicameralismo obligatorio las leyes relativas a las instituciones de la Comunidad germanófona, incluyendo la financiación de esta comunidad, ii) la legislación sobre partidos políticos; iii) la legislación sobre financiación de partidos políticos y gastos electorales; iv) las leyes relativas al estatuto de los senadores así como las relativas al Senado como institución. Se trata de un ámbito material que a primera vista puede parecer demasiado reducido y sucinto, pero desde el punto de vista de la afectación de la autonomía y competencias de los entes federados, queda asegurada la participación de los entes federados en las leyes especiales, que son el instrumento para la transferencia de competencias, así como para la financiación o para la atribución de la autonomía denominada constitutiva, que se corresponde con la autonomía autoorganizativa ${ }^{60}$.

El procedimiento bicameral obligatorio no solo acarrea la ida y venida (navette) de los textos legislativos entre las dos cámaras, imponiendo así la intervención

autorice una ley especial (federal, asimilable a las leyes orgánicas en España). El legislador regional puede reemplazar las provincias por colectividades supramunicipales, en cuyo caso se beneficiarán de la misma protección constitucional garantizada a las provincias. Si la supresión por una Región tiene lugar, las provincias subsistirán solo a efectos de delimitar el territorio de las entidades federadas y el de las regiones lingüísticas y seguirán sirviendo para la desconcentración de los servicios administrativos y jurisdiccionales estatales y regionales. Se completa así la regionalización de la administración local que estaba pendiente, si bien para algunos autores supone no abolir del todo las provincias, sino que más bien quedarán sustituidas por entidades del todo asimilables (asamblea elegida por sufragio universal directo con autonomía constitucionalmente garantizada) aunque se denominen colectividades supramunicipales. Aun así la reforma constitucional permitirá divisiones del territorio regional más racionales que las actualmente existentes. Cfr. M. UYtTENDAeLE, Voz «Provinces», M. UytTendaele - M. Verdussen, Dictionnaire de la Sixième réforme de l'État, op. cit., p. 715.

$60 \mathrm{La}$ autonomía constitutiva fue introducida por la reforma constitucional de 1993 que introdujo los arts. 118.2 y $123.2 \mathrm{CB}$ e inicialmente no fue reconocida a todos los entes federados, sino tan solo a la Comunidad francesa, la Comunidad flamenca y la Región valona. Cfr. C. Mertes, «L'autonomie constitutive des Communautés et des Régions», Courrier hebdomeidare du CRISP, n. ${ }^{\circ}$ 1650-1651, 1999, p. 5; M. UyTTENDAELE, «L'autonomie constitutive en droit fédéral belge. Réflexions sur l'unicité du pouvoir constituant dans un État fédéral», Administration publique trimestrielle, 1993, pp. 221 a 230. 
del Senado en las materias reservadas a dicho procedimiento, sino que además comporta para el nuevo Senado conservar el derecho de iniciativa (art. $75 \mathrm{CB}$ ), además de poder plantear preguntas escritas sobre dichas materias y de poder requerir la presencia de miembros del Gobierno (art. $100 \mathrm{CB}$ ).

\section{Materias que recaen en el bicameralismo opcional}

Excluidas las anteriores, las otras materias comprendidas en el art. $77 \mathrm{CB}$ quedan sometidas al procedimiento de bicameralismo opcional, por lo que el Senado retiene el derecho de avocar la tramitación de esos textos legislativos, pero la última palabra pertenece en última instancia a la Cámara de Representantes. Ahora bien, se plantea la cuestión de cómo ejercerá el derecho de avocación una cámara que deja de ser un órgano permanente. El Senado puede, en un plazo que no puede superar los treinta días, decidir que no ha lugar a enmendar el proyecto de ley o adoptar el proyecto tras haberlo enmendado. Si el Senado no decide dentro de ese plazo establecido, o si comunica a la Cámara de Representantes que su decisión de no enmendar el proyecto, ésta le transmitirá al Rey el proyecto para su sanción. El art. $78 \mathrm{CB}$ contiene las materias sujetas al bicameralismo opcional y el procedimiento para ejercer la facultad de avocación.

A partir de la reforma solo las materias enumeradas de manera taxativa quedan sometidas a este procedimiento. El Senado podrá solo avocar los textos relativos a ciertas materias que hasta ahora recaían dentro del procedimiento bicameral obligatorio, pero que tras la reforma constitucional, no pertenecen ya al ámbito material del art. $77 \mathrm{CB}$. Por tanto, las competencias legislativas perdidas en pie de igualdad con la Cámara de Representantes se han transformado en opcionales. De esta forma, en ciertas materias en las que hasta ahora el Senado era competente para examinarlas en pie de igualdad con la Cámara de Representantes mediante aprobación de una ley ordinaria, con la reforma pasan a formar parte del procedimiento de bicameralismo opcional al quedar sometidas al derecho de avocación. En caso de ejercerlo, el Senado examinará el texto ya aprobado por la Cámara de Representantes, pudiendo ratificarlo tal como está no introduciendo enmiendas o bien enmendarlo, en cuyo caso, vuelve a la Cámara baja, quien decide si ratificar su texto o bien enmendarlo ${ }^{61}$. Puesto que el listado de materias sobre las que se podrá ejercer dicho derecho es bastante reducido, el constituyente no ha estimado necesario suavizar sus condiciones de ejercicio, que

61 En la redacción anterior del art. 78 CB, último párrafo, se daba opción a la Cámara Baja a adoptar o a rechazar en todo o en parte las enmiendas del Senado, mientras que la nueva redacción parece ampliar las posibilidades, al permitir enmendar de nuevo el texto sin adoptar necesariamente las enmiendas del Senado: «Si el proyecto ha sido enmendado, el Senado lo transmite a la Cámara de Representantes, que se pronuncia definitivamente, bien adoptando, bien enmendando el proyecto de ley». 
siguen exigiendo una mayoría simple que suponga a su vez un tercio de cada uno de los grupos lingüísticos (art. 78.2 CB).

El Senado puede avocar y examinar las normas federales únicamente si afectan a las siguientes materias (mediante el procedimiento bicameral opcional del art. $78 \mathrm{CB}$ ): i) las leyes adoptadas en ejecución de leyes que exigen mayoría especial; ii) leyes relativas a la organización del Estado no comprendidas en el art. 77 CB (es decir las leyes a las que se refieren los arts. 5, 39, 115, 117, 118, 121,123, 127 a 129, 131, 135 a 137, 141 a 143, 163, 165, 166, 167.1, párrafo 3, 169, 170.2, párrafo 2, 170.3, párrafos 2 y 3, y 170.4, párrafo 2, 175 y 177 de la Constitución), iii) así como las leyes adoptadas en ejecución de las mismas, a excepción de la legislación sobre organización del voto automatizado; iv) las leyes adoptadas con arreglo al art. 169 CB para garantizar el respeto de las obligaciones internacionales o supranacionales y por las que el Estado puede sustituir a los entes federados; v) las leyes relativas al Consejo de Estado y jurisdicciones administrativas federales; vi) materias que pueden ser atribuidas al Senado por una ley especial para ser examinadas mediante el ejercicio del derecho de avocación. El derecho de avocación tiene repercusión sobre el derecho de iniciativa legislativa, que el Senado conserva, pero solo respecto a las materias sometidas al procedimiento bicameral obligatorio, de conformidad con el art. $77 \mathrm{CB}$. De este modo, y dado que la reforma constitucional ha suprimido el derecho de iniciativa legislativa del Senado en las materias que pertenecen al procedimiento de bicameralismo opcional, el art. 81 CB perdió enteramente su razón de ser, ya que se ocupaba de regular las materias que quedan sujetas al bicameralismo opcional, cuando la iniciativa procedía del Senado, de ahí que haya sido derogado.

El Senado no será ya sin embargo competente en una serie de leyes que, de acuerdo con el nuevo art. $77 \mathrm{CB}$, ahora quedan excluidas del procedimiento de avocación como: i) la ley de 11 de abril de 1994 de organización del voto automatizado; ii) la ley de 3 de julio de 1971 relativa al reparto de los miembros de las cámaras legislativas en grupos lingüísticos y sobre disposiciones relativas a los consejos culturales para la Comunidad cultural francesa y para la Comunidad cultural neerlandesa ${ }^{62}$; iii) el procedimiento de asentimiento de los tratados; iv) tampoco los proyectos o proposiciones de leyes de asentimiento a los acuerdos de cooperación podrán ser avocados por el Senado; v) por último, las

62 Esta ley contempla en sus arts. 4 a 6 el mecanismo conocido como «sonnette d'alarme idéologique», por el que la cuarta parte de los miembros de un Parlamento comunitario pueden suscribir una moción por la que declaran que determinadas disposiciones de un proyecto o de una propuesta de decreto en tramitación por la cámara, contiene una discriminación por razones ideológicas y filosóficas, pudiendo determinar, — previa admisión a trámite por los Presidentes de las cámaras del Parlamento nacional y los dos de los Parlamentos francófono y flamenco-, la suspensión del examen de dichas disposiciones en la Cámara de Representantes y el Senado, debiendo resolver éstas en cuanto al fondo, y solo si la moción se declara infundada el debate y tramitación de las disposiciones afectadas podrá ser retomado. Este mecanismo no debe ser confundido con la sonnette d'alarme comunitaria del art. $54 \mathrm{CB}$ ni con la «sonnette» del art. 31 de la ley especial de 12 de enero de 1989 relativa a las instituciones bruselenses. 
leyes sobre organización de juzgados y tribunales no podrán tampoco ser avocadas por el Senado.

Para avocar una materia a partir de ahora se podrá solicitar por una mayoría simple de senadores, con al menos un tercio de los senadores de cada grupo lingüístico. La avocación se puede plantear en los quince días siguientes al envío al Senado de la proposición de ley o proyecto de ley votados por la Cámara (art. 78.2 CB).

Es necesario insistir en que el Senado carece del derecho de iniciativa en todas las materias sujetas al procedimiento de avocación, pues de acuerdo con el nuevo art. $75 \mathrm{CB}$, el Senado no dispone ya del derecho de iniciativa legislativa respecto a las materias contenidas en el art. $78 \mathrm{CB}$. El Senado dispone de un mes a partir del día de la avocación para enmendar el proyecto. Un proyecto no puede ser avocado más que una sola vez. Tras haber sido enmendado por el Senado, el proyecto es devuelto a la Cámara, que adopta la decisión final (art. 78.2 in fine).

En cuanto a legislación sobre el derecho de sustitución temporal de la autoridad federal para asegurar el respeto de las obligaciones internacionales y supranacionales de Bélgica (reconocido en el art. 169 CB), tanto las leyes ordinarias que regulan el procedimiento de dicha sustitución por un lado, así como las leyes mediante las que la autoridad federal ejerce ese derecho de sustitución, forman parte de las materias sometidas al procedimiento de bicameralismo opcional (art. 78.1.3. ${ }^{\circ} \mathrm{CB}$ ), a diferencia del bicameralismo obligatorio al que estaba sometida esta última según el anterior art. 77.1. ${ }^{\circ} .7 \mathrm{CB}^{63}$. En cambio, la legislación que define los principios o bases del ejercicio del derecho de sustitución continuará formando parte de las materias sometidas al bicameralismo obligatorio, ya que esos principios según la Constitución, deben figurar en una ley especial y como tal solo puede ser aprobada mediante el procedimiento legislativo de bicameralismo paritario, al exigirlo expresamente así el art. 77.3. ${ }^{\circ} \mathrm{CB}$. Así pues, la reforma constitucional no ha cambiado el marco normativo del derecho de sustitución, que fue introducido en su día, — ante la falta de un procedimiento de coerción o de ejecución federal (Bundeszwang) en la Constitución— ${ }^{64}$, por el art. 16.3 de la Ley especial de 8 de agosto de 1980 que instituía las regiones, y que fue posteriormente constitucionalizado en la reforma de 1993 (art. 169 CB), pero que nunca se ha ejercido ${ }^{65}$.

63 La fuerte revisión a la baja de las competencias del Senado en materia de relaciones internacionales encuentra aquí una excepción, no tanto por mitigar dicha reducción, sino por pertenecer las leyes de sustitución de los entes federados a la categoría de las leyes especiales, sujetas al procedimiento bicameral obligatorio. Cfr. J. Sautois, M. UytTendaele (dirs.), La sixième réforme de l'État (2012-2013): Tournant historique ou soubresaut, op. cit., p. 99.

64 Cfr. J.-V. Louis - A. Alen, «La Constitution et la participation à la Communauté européenne», Revue Belge de Droit International, 1994/1, p. 97.

65 El mecanismo del poder de sustitución solo puede ser activado si hay una condena expresa de Bélgica por una instancia internacional, lo cual ha sido objeto de crítica doctrinal, y puede operar ante el incumplimiento de obligaciones derivadas de tratados internacionales, incluidas las que son de competen- 
Una importante novedad es que, como hemos apuntado, en adelante una ley especial puede incorporar nuevas materias al procedimiento de bicameralismo paritario o también introducir nuevas materias sobre las que el Senado puede ejercer el derecho de avocación (art. $77 \mathrm{CB}$ in fine y art. 78.1 CB in fine).

Puesto que el Senado no participa ya en el procedimiento de asentimiento de los tratados, el 75 CB ha quedado derogado. La idea de que el Senado pudiera ratificar los denominados tratados mixtos en nombre del conjunto de los entes federados con un derecho de avocación por parte de sus Parlamentos no ha sido por tanto finalmente acogida ${ }^{66}$. El Senado queda así marginado de una tarea sobre la que habría podido reposar el modelo propuesto por algunos constitucionalistas, el de un Senado concebido como cámara diplomática investida de competencias en los asuntos europeos e internacionales, mientras que la Cámara de representantes se especializaría en los asuntos internos ${ }^{67}$.

\section{El procedimiento legislativo de las leyes especiales}

Las mayorías exigidas no han sufrido modificaciones, por lo que las leyes ordinarias seguirán siendo aprobadas por mayoría absoluta. Lo mismo cabe decir de las leyes especiales y de reforma o de coordinaciones de la Constitución, en las que se siguen exigiendo mayorías cualificadas especiales. Sin embargo, donde sí se han producido cambios es en el listado de leyes especiales, cuyo ámbito material ha sido ampliado, ya que el nuevo art. 157 bis de la Constitución, dispone que los elementos esenciales del empleo de lenguas en el partido judicial de Bruselas solo podrán ser modificados mediante ley adoptada por la mayoría prevista en el art. 4 CB. Siguiendo una técnica «sorprendente», como la ha calificado algún autor $^{68}$, aunque utilizada en ocasiones anteriores, el constituyente ha pretendido elevar al rango constitucional un aspecto que afecta a los equilibrios que sostienen la «paz comunitaria» belga. Dado que la ley de 19 de julio de $2012^{69}$ es una ley ordinaria que no precisa en qué preceptos se contienen dichos elementos esenciales $^{70}$, será de todo punto necesario una labor interpretativa para inferir qué

cia exclusiva de la instancia federada.Cfr. A. Schaus, «L'exécution des traités», Revue belge de Droit International, 1994/1, p. 70.

66 La exclusión ha sido criticada por la doctrina, que entiende que el Senado debería haber conservado un papel específico en lo que se refiere a los tratados mixtos. Cfr. A. FEYT - P. VANDERnACHT, «La réforme du Sénat, un tableau inachevé...», op. cit., p. 99.

67 Vid. F. Delpérée, La Constitution de 1830 à nos jours, Bruxelles, Éditions Racine, 2006, p. 131.

68 Vid. F. Gosselin, «La réforme de l'arrondissement judiciaire de Bruxelles», J. SAUTOIS, M. UYTTENDAELE (dirs.), La sixième réforme de l'État (2012-2013): Tournant historique ou soubresaut, op. cit., p. 385.

69 En su dictamen, el Consejo de Estado aconsejaba precisar cuáles son esos «elementos esenciales»e incluso avanzaba la conveniencia de dividir el texto de la ley en una parte de elementos esenciales y otra con las demás disposiciones no esenciales.

70 Cfr. B. Martel, J. VanPRAet, «La réforme de l'arrondissement judiciaire de Bruxelles», Eubelius, Septembre, 2012. 
preceptos contienen dichos elementos, que materialmente tendrán carácter de ley especial $^{71}$.

Asimismo, el constituyente de 2014 ha incluido en el art. 63, §4 CB, —que reserva a la ley la determinación de las circunscripciones electorales y las condiciones para ser elector y el desarrollo de las operaciones electorales-, una disposición que exige que solo mediante ley especial (art. 4 CB) se podrán modificar las modalidades especiales que la ley establece a fin de garantizar los intereses legítimos de neerlandófonos y francófonos en las elecciones. El nuevo art. 168 bis $\mathrm{CB}$ ha establecido ese mismo régimen (de ley especial) para las elecciones al Parlamento europeo en esos mismos municipios de la antigua provincia de Brabante. La ley de división de la circunscripción electoral de Bruxelles-Hal-Vilvorde ha intentado preservar los derechos fundamentales de esos ciudadanos estableciendo, para las elecciones a la Cámara de Representantes y en las elecciones al Parlamento Europeo, la creación en la antigua provincia de Brabante de tres circunscripciones electorales: una circunscripción para el Brabante flamenco, y una circunscripción electoral específica de Bruselas-Capital, cuyo territorio coincide con el del distrito administrativo de Bruselas-Capital. Dentro del Brabante flamenco se ha creado un cantón electoral que comprende seis municipios periféricos de Bruselas. Ambas circunscripciones tienen garantizado un régimen particular al resto (como ocurre por ejemplo con la aplicación de una barrera electoral distinta $)^{72}$. Pero lo que ha motivado posibles dudas de inconstitucionalidad ha sido que los art. 4 y 27 de la Ley de 9 de julio de 2012 (que introduce un art. 89 ter en el Código electoral), en aplicación de las modalidades especiales a las que se refieren los arts. 63.4 y 168 bis CB, les ofrece a los votantes de los seis municipios periféricos de estas nuevas circunscripciones votar, tanto en las elecciones a la Cámara de Representantes como en las elecciones al Parlamento europeo, $-\mathrm{y}$ ya sean neerlandófonos o francófonos-, por una lista de la circunscripción del Brabante flamenco o por una lista de la circunscripción de Bruselas-Capital. La ley 9 de julio de 2012 terminó por ser recurrida ante el TC que declaró, en su Sentencia n. ${ }^{\circ} 72 / 2014$ de 8 de mayo, que «no es competente para pronunciarse sobre una diferencia de trato o sobre la limitación de un derecho fundamental que resulta de una elección que el Constituyente ha efectuado (considerando B.14.1)». Importa destacar que con esta reforma constitucional se ha aportado por fin una solución a la inconstitucionalidad de la escisión de la circunscripción Bruxelles-Hal-Vilvorde, declarada por el TC (en aquel momento Cour d'arbitrage), en su Sentencia n. ${ }^{\circ} 73 / 2003$ de 26 de mayo de 2003.

71 La Ley de 19 de julio de 2012 sobe reforma del distrito judicial de Bruselas (M.B., 22 août 2012, p. 49.293) modifica distintas disposiciones del código Judicial y de la Ley de 1935 sobre uso de lenguas en procesos judiciales por el desdoblamiento de tribunales y fiscales del distrito judicial de Bruselas.

72 Cfr. J. Velaers, «De zesde staatshervorming, eerste fase: BHV, de randgemeenten, Brussel en de democratie», Rechtskundig Weekblad, Parte I envol. 76, n. ${ }^{\circ} 26$ (2013), pp. 1002 a 1030 y Parte II en vol. 76, n. 27 (2013), pp. 1042 a 1061. 


\section{Materias del procedimiento monocameral (residual)}

Según lo dispuesto en el párrafo $4 .^{\circ}$ de la disposición transitoria del art. 195 $\mathrm{CB}$, las «competencias legislativas residuales» se atribuyen a la Cámara de Representantes. Así pues, las materias que en virtud del juego de los arts. 77 y 78 no se encuentren mencionadas, corresponden al procedimiento monocameral al que quedarán sujetas las materias a las que se refiere el art. 195 CB.

Del nuevo marco general resultante se obtiene que las materias que obligatoriamente quedan sometidas a un procedimiento bicameral son las relativas a la reforma de la Constitución o bien las que afectan a cuestiones institucionales. En concreto, la Cámara de Representantes y el Senado serán competentes en un pie de igualdad únicamente para las normas federales que afecten a estas materias (sometidas al procedimiento bicameral obligatorio del art. $77 \mathrm{CB}$ ): la declaración de revisión de la Constitución, así como la revisión y coordinación de la Constitución; las materias que deben ser aprobadas por ambas Cámaras legislativas en virtud de la Constitución; las leyes que se aprueban mediante mayoría especial ex art. $4 \mathrm{CB}$; las leyes sobre instituciones de la Comunidad germanófona y su financiación, las leyes sobre financiación de partidos políticos y control de gastos electorales, las leyes sobre organización del Senado y el estatuto de los senadores; y además otras materias que puedan ser añadidas mediante ley especial para ser tramitadas en pie de igualdad. De aquí se sigue que el Senado mantiene su competencia en todo lo relativo a libertades y derechos fundamentales de los ciudadanos y en lo que se refiere a la organización del poder.

El resto de materias no encuadrables en alguno de los procedimientos bicamerales de los arts. 77 y $78 \mathrm{CB}$, automáticamente se entienden remitidas al procedimiento monocameral. Lo llamativo es que el sometimiento al procedimiento monocameral no equivale a la tramitación en una sola lectura, pues el Acuerdo institucional para la Sexta reforma del Estado de 11 de octubre de 2011 contemplaba que el Reglamento de la Cámara de Representantes debe prever una segunda lectura y así se ha constitucionalizado en el nuevo art. $76 \mathrm{CB}$, párrafo tercero ${ }^{73}$. La defensa de un monocameralismo sin que ello comporte renunciar a una segunda lectura ya había sido lanzada en la doctrina muchos años atrás ${ }^{74}$. Incluso existía el precedente en el Parlamento de la Comunidad flamenca ${ }^{75}$. Esta previsión se ha incorporado al nuevo art. $76.3 \mathrm{CB}$, pero no va a exigir sin embargo la reforma de

73 Art. 76 CB: «Le règlement de la Chambre des représentants prévoit une procédure de seconde lecture».

74 Cfr. J. Sohier, Bicaméralisme et Etat fédéral. La réforme du Sénat belge, Centre d'Etudes du Fédéralisme, juin, 1990, p. 11.

75 Cfr. Didier Reynders, «Table ronde sur la réforme du Sénat», en La réforme du Sénat, Actes du colloque sur la réforme du Sénat organisé par le Centre de Droit public de l'Université Libre de Bruxellesle 6 octobre 1989, Bruylant, Bruxelles, 1990, pp. 155. 
Reglamento de la Cámara de Representantes, puesto que ya existe la segunda lectura en dicha cámara. Lo que se constata es que todos los procedimientos legislativos, con o sin intervención del Senado, por mandato constitucional, deben pasar una segunda lectura.

Una de las consecuencias de haber limitado de manera drástica los proyectos de ley que pueden ser objeto del derecho de avocación por el Senado y de haber reducido los plazos en los que se puede ejercer, ha sido la propuesta de abolir el art. $80 \mathrm{CB}$ (procedimiento de urgencia), ya que el Senado solo podrá realizar una única lectura para introducir enmiendas. Del mismo modo, el art. $81 \mathrm{CB}$, que regulaba por su parte el procedimiento de bicameralismo opcional para determinadas materias (contempladas en el art. $78 \mathrm{CB}$ ) en las que el Senado podía enviar a la Cámara de Representantes una proposición de ley ${ }^{76}$, también ha perdido su razón de ser al quedar suprimido el derecho de iniciativa legislativa en las materias sujetas al bicameralismo opcional ${ }^{77}$.

\section{LA INDISOLUBILIDAD ORDINARIA DEL NUEVO SENADO Y LOS PERÍODOS DE SESIONES.}

Hasta ahora existían cuatro causas de renovación completa del Senado: el final natural de la legislatura tras cuatro años (art. 70 CB); la disolución de la Cámara de Representantes que entraña la disolución automática del Senado (art.46. 4 CB); la adopción de una declaración de reforma de la Constitución (art. 195.2 CB) y la vacante del Trono (art. $95 \mathrm{CB}$ ).

A partir de ahora, tras la reforma constitucional, el Senado no se disolverá o se renovará completamente más que en el caso de provisión del Trono vacante (art. $95 \mathrm{CB}$ ), o tras la adopción de una declaración de reforma constitucional (art. 195 CB). No se disuelve el Senado por tanto cuando la Cámara de Representantes sea disuelta por perder el Gobierno una moción de censura sin propuesta simultánea de candidato alternativo (art. 46.1 CB), o una cuestión de confianza (art. 46.2 CB), o por dimisión del Gobierno si asiente a ello la Cámara de Representantes por mayoría absoluta (art. $46 \mathrm{CB}$ párrafo cuarto).

Además, y dado que tras la reforma la composición del Senado se basa sobre los resultados en elecciones diferentes que no tienen por qué coincidir necesariamente, el Senado puede pasar a renovarse de manera parcial y periódica, puesto

76 Las materias del art. $78 \mathrm{CB}$ se solapaban con las materias reservadas por el art. 77 al procedimiento bicameral obligatorio, dado que coexistían ambas en los denominados proyectos de ley mixtos, lo que generaba múltiples problemas a la hora de determinar el orden de entrada de proyectos en una o en otra cámara. Cfr. C. Nyssens, «Comment s'établit la règle de droit aujourd'hui? Le point de vue d'une assistante parlementaire, B. ЈАDОт — F. OST (dirs.), Élaborer la loi aujourd'hui, mission impossible?, Publications des Facultés universitaires Saint-Louis, Bruxelles, 1998, p. 114.

77 Doc. Parl., 5-1741 Annales du Sénat: 26 et 28 novembre 2013. 
que la disolución o renovación del Senado no tiene como efecto la convocatoria de elecciones en los Parlamentos de Comunidad o de Región.

\section{La desaparición de caducidad de textos ya introducidos}

Se ha pretendido evitar que la Cámara que examina un texto en segundo lugar pueda adoptar un texto que no sería aprobado por la nueva mayoría de la cámara que habría examinado el texto en primera lectura. Hasta ahora la ley de 5 de mayo de 1999 sobre efectos de la disolución de las Cámaras legislativas respecto de los proyectos en tramitación, determina que todo proyecto o proposición de ley se considera como no existente en caso de disolución de las cámaras. Ahora bien, puesto que tras la reforma del Senado, la disolución de ambas cámaras no tendrá lugar necesariamente de manera automática, ha sido necesario adaptar la citada norma legal.

Para ello se ha previsto que la caducidad de las proposiciones y proyectos de ley no dependerá ya a partir de ahora de la disolución y renovación completa de la Cámara de Representantes. Para eliminar la caducidad a la que estaban sometidos los textos en el Senado por la disolución de la otra cámara, se han derogado el párrafo 2 del art. 2 y los arts. 3 a 5 de la ley de 5 de mayo de 1999 sobre efectos de la disolución de las Cámaras legislativas respecto de los proyectos en tramitación ${ }^{78}$.

\section{El desacompasamiento de mayorías entre las cámaras}

Hasta ahora, y tras la reforma constitucional del Senado en 1993, las elecciones a ambas cámaras eran simultáneas en virtud del anterior art. $46 \mathrm{CB}^{79}$, a partir de ahora se ha introducido la posibilidad, que puede darse tras la reforma, de que la legislatura de la Cámara de Representantes no coincida con la del Senado. Tras la reforma constitucional del sistema bicameral (arts. 46.6, 65.3, y 118.2, párrafo $4, \mathrm{CB}$ ) se pueden dar cuatro tipo de situaciones: a) que las dos cámaras sean disueltas tras la adopción de una declaración de reforma constitucional, en cuyo caso Cámara y Senado se renuevan por completo; b) que las elecciones a la Cámara de Representantes coincida con la de los parlamentos de comunidad y de región, en cuyo caso Cámara y Senado se renovarán íntegramente; c) que las elec-

78 En virtud del art. 3.1 de la mencionada ley sobre efectos de la disolución de las cámaras, de 5 de mayo de 1999, los proyectos de ley quedaban pendientes durante la fase contemplada en el art. 78.2 CB anterior a la reforma constitucional, y en el que se establecía que el Senado no podía examinar el proyecto de ley si no lo solicitaban al menos 15 senadores, de donde se seguía que los proyectos de ley sobre materias incluidas en el art. $78 \mathrm{CB}$ que hubiesen sido relevados de caducidad por el Senado, no podían ser examinados sino tras haber sido avocados, con independencia de que hubieran sido ya avocados o no bajo la legislatura anterior.

79 En su penúltimo párrafo, el anterior art. 46.2CB disponía que «La disolución de la Cámara de Representantes entraña la disolución del Senado». 
ciones a la Cámara de Representantes no coincidan con las de los parlamentos de comunidad y de región, en cuyo caso la Cámara de Representantes se renovará íntegramente, pero en el Senado solo se producirá la renovación de los senadores cooptados que son diez frente a los 60 del total de senadores; d) que las elecciones a los parlamentos de comunidad y de región no coincidan con las de la Cámara de Representantes, en cuyo caso ésta no se renueva, pero sí los senadores de los entes federados que suman un total de 50 sobre el total de $60^{80}$.

La legislatura de la Cámara baja a partir de la reforma es la que se considera «legislatura federal» por el art. $46 \mathrm{CB}$, párrafo 6 , lo que tiene efectos por ejemplo en órganos bicamerales como la comisión de concertación, cuya instalación y disolución que tiene como duración una legislatura, tendrá lugar teniendo como referencia el comienzo y final de legislatura de la Cámara de Representantes ${ }^{81}$.

$\mathrm{Si}$, de una parte, las elecciones federales a la Cámara de Representantes se celebran en una fecha y las elecciones a los parlamentos y entidades federadas sobre las que se nombran 50 de los 60 senadores se eligen en otras, puede ocurrir que la mayoría gubernamental en la segunda cámara se vea modificada en alguno de los grupos lingüísticos tras la celebración de elecciones al Parlamento valón, al Parlamento de Bruselas-Capital, etc. Puesto que la Cámara de Representantes queda configurada como un Parlamento de legislatura y puesto que ya no existen elecciones al Senado, el gobierno puede ver perder su mayoría en esta cámara. Resulta no obstante manifiesto el interés inicial del legislador de la reforma constitucional, por convocar elecciones simultáneas cada cinco años, a la Cámara de Representantes, a los Parlamentos de Comunidades lingüísticas, a los Parlamentos de región y al Parlamento europeo.

\section{Períodos de sesiones}

El Senado ha quedado tras la reforma constitucional configurado como un órgano no permanente, lo que quiere decir que no celebrará Plenos permanente-

80 A pesar de ello, dado que por imposición del art. 117.2 CB las elecciones regionales coinciden con las elecciones al Parlamento europeo, y puesto que las elecciones a la Cámara de Representantes tras la reforma constitucional tienen lugar necesariamente el día de las elecciones europeas, todas las elecciones han empezado coincidiendo en la misma fecha. Sin embargo, tras la ampliación de la autonomía constitutiva a la facultad de disolución anticipada de los Parlamentos comunitarios y regionales, tal concomitancia debería dejar de ser la regla general para pasar a ser más bien algo anómalo. Cfr. T. WINGAARD - O. LEGRAND, «Le renouveau politique: questions choisies», J. SAUtois, M. UYTTENDAELE (dirs.), La sixième réforme de l'État (2012-2013): Tournant historique ou soubresaut, op. cit., p. 202.

81 La Comisión parlamentaria de concertación fue introducida por el art. 82 CB y regulada por la Ley de 6 de abril de 1995. Tiene una composición paritaria de 11 senadores y 11 miembros de la Cámara de Representantes, Su función primordial es la de resolver los eventuales conflictos de competencia que puedan surgir entre las dos cámaras respecto al procedimiento de elaboración de las leyes. Se encarga también de conceder ampliación en los plazos que tiene el Senado para ejercer el derecho de avocación, suspendiendo el voto en la cámara baja hasta que el Senado adopte su decisión (art. 2.1 de la ley). 
mente durante el período de sesiones. El art 30 del nuevo Reglamento del Senado de 13 de diciembre de 2013 ha fijado en efecto en ocho el número de Plenos anuales ordinarios que como máximo el nuevo Senado podrá celebrar, lo cual restringe sobremanera la posibilidad de ejercer el derecho de avocación dados los estrictos plazos impuestos. Tras la reforma y la designación de senadores, la Mesa ha decidido que se celebre un Pleno un viernes de cada mes. El art. 30 precisa también que será la Mesa la que decida la convocatoria de un Pleno extraordinario al igual que la no convocatoria de un pleno ordinario cuando no se haya inscrito ningún punto en el orden del día.

El art. $44 \mathrm{CB}$, párrafo primero 1, dispone que las cámaras se reúnen de pleno derecho cada año, el segundo martes del mes de octubre, a menos que hayan sido convocadas antes por el Rey. Asimismo, deben de permanecer reunidos cada año al menos durante 40 días. El tenor de ambos preceptos parece poco conciliable con el nuevo carácter no permanente del Senado. Se desprende de dicha regulación que se debe de distinguir a los efectos de precisar que es un órgano no permanente, entre la noción de «session» y la noción de «réunion». Cada nueva sesión de apertura anual va precedida de un arrêté real, pero en adelante se estima que nada impedirá que la Cámara de Representantes o el Senado se reúnan cuando lo juzguen útil. Sin embargo, se ha apuntado que la reducción de sesiones en el Senado no ha de ser necesariamente un obstáculo para poder avocar un proyecto de ley, ya que la avocación constituye un acto administrativo que se presenta por los grupos parlamentarios y que se tramita por los servicios de la cámara.

\section{La duración de la Legislatura}

La última de las disposiciones del art. $46 \mathrm{CB}$ dispone que en caso de disolución anticipada de la Cámara de Representantes, la nueva legislatura federal no podrá durar más allá del día de las elecciones al Parlamento europeo siguiente a la disolución. Esta regla ya se había introducido anteriormente para las elecciones regionales y comunitarias, que se celebran el mismo día de las elecciones europeas desde 1999, lo cual ha traído consigo el emparejamiento de todas las elecciones el 25 de mayo de $2014^{82}$. Asimismo, en virtud de esta regla del art. $46 \mathrm{CB}$, en caso de disolución anticipada de la Cámara la nueva legislatura federal finaliza el día de las primeras elecciones que haya al Parlamento europeo o, lo que es igual, la Cámara no podrá ser disuelta de nuevo después de menos de un año, por ejemplo. El derecho de disolución anticipada a los Parlamentos de los entes federados

82 La perpetuación de esa simultaneidad entre elecciones federales y elecciones regionales exige no obstante la aprobación de una ley especial. En ausencia de dicha ley, la coincidencia de las elecciones federales y regionales en 2014, con un acoplamiento de duración de las legislaturas respectivas, puede crear una dinámica que facilite la simultaneidad de elecciones, pero no está desde luego garantizada, ya que esa simultaneidad podría romperse en caso de disolución anticipada del Parlamento federal. 
y de organizar elecciones anticipadas no está reconocido por el momento ni se ha debatido en esta reforma constitucional, pues no formaba parte del Acuerdo institucional para le reforma.

\section{REDUCCIÓN DE OTRAS COMPETENCIAS}

La función de control político del Senado sobre el gobierno federal, ya de por sí fuertemente limitada con la reforma de 1993, se ha suprimido completamente con la actual reforma. En efecto ya en la reforma de 1992-1993 se suprimió la confianza al gobierno y el voto del Presupuesto, que se reservaban exclusivamente a la Cámara de Representantes. El Senado fue despojado además de la posibilidad de crear comisiones de investigación, de plantear preguntas orales o de registrar solicitudes para pedir explicaciones al gobierno. Solo conservó el derecho de plantear preguntas escritas solo sobre cuestiones referidas a materias competencia del Senado.

El art. 100, párrafo 2, sigue reconociendo que: «La Cámara de representantes puede requerir la presencia de ciertos ministros en particular. El Senado puede requerir su presencia en el marco de los procedimientos de los artículos 56, 77 o 78. Para el resto de materias puede solicitar su presencia». Por consiguiente, el Senado conserva el derecho de requerir la presencia de los ministros para abordar las materias pertenecientes al bicameralismo obligatorio o al bicameralismo opcional o virtual. Pero sin que sea posible plantear preguntas por escrito ni interpelarles. Asimismo el art. $56 \mathrm{CB}$ ya no permite la creación de comisiones de investigación en el Senado.

El Senado conserva en cambio otras competencias como la posibilidad de elaborar informes. El art. 56 de la $\mathrm{CB}$ ha sido modificado de manera que, además de reconocer el derecho de investigar exclusivamente solo a la Cámara de Representantes, respecto al Senado, dispone que a petición de quince de sus miembros, de la Cámara de Representantes, de un Parlamento de comunidad o de región o del Rey, puede decidir por mayoría absoluta de los votos emitidos, con al menos un tercio de votos emitidos por cada grupo lingüístico, que una cuestión que tenga asimismo consecuencias para las competencias de las comunidades o de las regiones, sea objeto de un informe. El informe se aprueba por mayoría absoluta de sufragios emitidos, con al menos un tercio de sufragios en cada grupo lingüístico» por el Pleno de la cámara (art. 66 RS, párrafo 9). Todo senador podrá formular observaciones o recomendaciones a las conclusiones del informe según un procedimiento escrito (art. 66 RS párrafo 7). Se contempla también que sean varias las comisiones de la cámara que pueden participar en su elaboración a criterio de la Mesa del Senado.

En el marco de dicha competencia el Senado puede solicitar la presencia de los ministros (art. 100 CB in fine). La regulación del informe no exige la intervención del legislador, puesto que el Senado no dispone ya de competencias atribui- 
das al juez de instrucción como hasta ahora, con la regulación que ha estado vigente $^{83}$. Cuando se elabore un informe el Senado no podrá ahora citar expertos o testigos, interrogarles bajo juramento o forzarles a prestar su testimonio. El Senado podrá de todos modos llamar a expertos para redactar el Informe, que no se debe confundir con el Informe de una comisión de investigación, que tiene naturaleza para-judicial. No obstante, resulta contradictorio que existan mayorías especiales para iniciar y aprobar informes, pues no parece lógico que sea más fácil adoptar una ley o una resolución que aprobar un informe.

El art. 57 CB regula el derecho de petición, formando parte de las herramientas de las que disponen las cámaras para ejercer el control político sobre el gobierno. La reforma ha suprimido de dicho precepto toda referencia al Senado concentrando en la Cámara de representantes la posibilidad de enviar peticiones a los ministros y a obligar a los ministros a justificarse en cuanto al contenido. El art. $57 \mathrm{CB}$ puede no obstante prestarse a confusión con el enunciado del art. 28 CB. El nuevo art. 57 dispone que «Se prohíbe presentar en persona peticiones a las cámaras. La Cámara de Representantes tiene el derecho de remitir a los ministros las peticiones dirigidas a ellos. Los ministros estarán obligados a dar explicaciones sobre su contenido cada vez que la Cámara se lo exija». El enunciado del art. 28 CB por su parte expresa que: «Todos tienen el derecho de dirigir peticiones firmadas por una o varias personas. Las autoridades constituidas tienen el derecho de dirigir peticiones en nombre colectivo». El derecho fundamental de los ciudadanos a dirigir peticiones a las autoridades públicas, regulado por el art. $28 \mathrm{CB}$, no resulta modificado por el art. $57 \mathrm{CB}$. En efecto, lo que se ha suprimido es que el Senado pueda dirigir a los ministros peticiones y obligarles a que respondan. Los ciudadanos por su parte conservan el derecho de dirigir al Senado peticiones relativas a materias en las que es competente. La reforma del art. 57 $\mathrm{CB}$ afecta por tanto solo a la tramitación que se haya de dar a las peticiones.

Las reuniones de comisiones se verán asimismo reducidas de manera sensible, al desaparecer las preguntas al gobierno y el derecho de iniciativa de los senadores, además de verse restringido el derecho de avocación de los textos aprobados por la Cámara de Representantes. El 6 de octubre de 2014 la Mesa del Senado adoptaba la decisión de crear solo 3 comisiones permanentes: la Comisión de asuntos institucionales, una comisión para materias transversales entre autoridades federales y Comunidades y una comisión para materias transversales entre autoridades federales y regiones. Las tres comisiones se reunirán cada dos semanas ${ }^{84}$.

A excepción de los nombramientos de los magistrados del Tribunal Constitucional $^{85}$, y de los consejeros de Estado y sus asesores ${ }^{86}$, o de los miembros del

83 Art. 4 de la Ley de 3 de mayo de 1880 sobre investigaciones parlamentarias.

84 Para la anterior regulación en el Reglamento del Senado, cfr. N. LAGASSE \& X. BAESELEN, Le droit d'enquête parlementaire, Bruxelles, Bruylant, 1998, pp. 43 y ss.

85 Art. 32 de la Ley especial de 6 de enero de 1989.

86 Arts. 70 y 80 de las leyes coordinadas sobre el Consejo de Estado. 
Consejo Superior de Justicia ${ }^{87}$, el Senado no será competente para otros nombramientos.

La reforma del Senado también ha tenido consecuencias en el control que ejercía anteriormente sobre los servicios de policía y los de información. El control de estos servicios tras la reforma constitucional no será llevado a cabo por el Senado, sino que de modo exclusivo corresponde a la Cámara de Representantes.

Asimismo, el Senado no será ya competente en cuestiones éticas, puesto que el debate que tiene lugar tras las recomendaciones de la Comisión de evaluación en materia de aborto o la Comisión de control y evaluación en materia de eutanasia se llevarán a cabo a partir de hora en la Cámara de Representantes en lugar del Senado.

Por otra parte, el personal administrativo del Senado ha sufrido una reducción, de manera que se ha tenido que decidir la transferencia de algunos de ellos a otros Parlamentos.

Por último, la intervención del Senado en lo que se refiere a la Corona, no ha experimentado variaciones (arts. 85, 86, 87, 90, 91, 92, 93 y 95 CB) por lo que esta materia sigue estando sometida al denominado «bicameralismo integral» de las cámaras reunidas en sesión conjunta.

\section{CONCLUSIONES}

El objetivo perseguido en esta última reforma constitucional ha sido el de hacer del Senado una cámara de inordinación de las entidades federadas, en el que Comunidades y Regiones participan a través de sus parlamentos en la organización y funcionamiento del Estado, convirtiéndolo en un foro que sirva de lugar de encuentro a las entidades federales ${ }^{88}$. Sin embargo, a la vista de sus competencias, solo de manera muy limitada se puede afirmar que el nuevo Senado participa en la gestión del Estado, de manera que difícilmente podrá convertirse en un lugar de encuentro y de concertación de los parlamentarios comunitarios y regionales para cooperar en la política estatal, sino que más bien se corre el riesgo de que sirva para defender los propios intereses en lugar de alcanzar acuerdos, como hasta ahora ha venido ocurriendo ${ }^{89}$. Desde este punto de vista, la nueva reforma constitucional no ha perseguido aproximarse a modelos como el del Bundesrat alemán, en el que los estados colaboran en la confección de las leyes, teniendo incluso un derecho de participar en la elaboración anual del presupuesto federal. En cuanto a competencias, el intento por superar un Senado anclado en el bicameralismo decimonónico, ha supuesto desde luego una mayor especialización en

87 Art. 151.2 de la Constitución.

88 Sénat, Document législatif $n .^{\circ}$ 5-1720/1, 19 juillet 2012, p. 2.

89 Vid. Chambre, Doc. 53 3173/ (2013/2014), p. 3. 
sectores materiales específicos que pueden encontrarse en otros modelos de bicameralismo territorial. Respecto a la composición, se puede objetar que la lógica de los grupos lingüísticos no ha sido sustituida por una clave representativa eminentemente territorial ${ }^{90}$, de manera que parece seguir subyaciendo una cierta lógica confrontacional en una cámara que estaba llamada a ser el espacio de concertación y de pacificación regional por excelencia ${ }^{91}$. Si a ello se añade que también la Cámara de Representantes es un reflejo proporcional de cada grupo lingüístico, la diferenciación de la representación a la que tiende el bicameralismo queda en entredicho ${ }^{92}$.

En realidad este nuevo Senado no se aparta de otros intentos de reforma como el modelo propuesto por los Informes Gol-Leemans redactados por una comisión mixta parlamentaria para la reforma de las instituciones integrada por miembros de ambas cámaras, de 23 de abril de 1990. El gran parecido de esta propuesta con el Senado surgido de la reforma de 2012-2014 vendría a dar credibilidad al cierre en falso de la anterior reforma, en la que se asumió la especialización del Senado en una serie de asuntos, no todos ellos vinculados al carácter territorial o federal, pero manteniendo la posibilidad de intervenir en los procedimientos legislativos en una generalidad de materias, por lo que no desaparecía su función de cámara de segunda lectura o de reflexión ${ }^{93}$. El logro por tanto del nuevo Senado ha sido el de convertirse en cuanto a su composición y funciones en una cámara modelada sobre el arquetipo de cámara territorial. Se admite en este sentido que el Senado resultante de la reforma supone una ruptura respecto a al Senado que se deja atrás ${ }^{94}$. Aun así, el Senado resultante no puede asimilarse a ninguno de los modelos federales conocidos, por más que hayan querido buscarse similitudes con el Bundesrat alemán. Existen además elementos que debilitan su carácter de cámara territorial de un Estado federal, como la coincidencia entre elecciones legislativas, regionales y europeas, si bien por decreto (ley infraestatal) las regiones y comunidades pueden derogar dicha coincidencia por ofrecerles expresamente dicha posibilidad el art. $117 \mathrm{CB}$ en su tercer párrafo ${ }^{95}$.

90 De hecho, la composición numérica de los grupos lingüísticos en el Senado sigue manteniendo casi los mismos equilibrios entre grupos lingüísticos existentes antes de la reforma constitucional, siendo mayoritario el grupo de senadores neerlandeses. Cfr. R. Dandoy, J. Dodeigne, M. Reuchamps \& A. VandeleeNE, «The new Belgian Senate. A (dis)continuedevolution of federalism in Belgium?», Representation, 2015.

91 Así lo señala Ann Feyt, para quien la dialéctica Norte-Sur se mantiene al perpetuar la distribución en un grupo lingüístico francés y otro neerlandés. Cfr. A. FEYT, «La réforme du Sénat, un tableauinachevé...», op. cit., p. 87.

92 Cfr. M. Verdussen, «La dernièreréforme du Sénat de Belgique», op. cit., p. 83. p. 162 .

93 Cfr. «El Senado belga», en Ante el futuro del Senado, Institutd'EstudisAutonòmics, Barcelona, 1996,

94 Cfr. H. Matтhijs, «De hervorming van de Senaat», C.D.P.K (Chroniques de droitpublic - Publiekrechtelijkekronieken), 2013, vol. 1, p. 57.

95 K. MuYlle, «De hervorming van de Senaat en de samenvallendeverkiezingen: eenprocessie van Echternachnaar de federale (model)staat?», A. Alen, B. Dalle, K. Muylle, W. Pas, J. Van Nieuwenhove, W. Verrijdt (eds.), HetfederaleBelgië na de ZesdeStaatshervorming, Brugge, Die Keure, 2014, 103-124. 
El flanco más débil de esta reforma no obstante es el mismo que está asociado a todas las reformas de las segundas cámaras que no logran territorializar el voto de los senadores, ya que en la medida en que el voto siga teniendo una afiliación política, no es dable reconocer como sujeto representado al territorio al que representan. El voto plural aparece por tanto como un obstáculo en el que la disciplina de partido se interpone a una posible reagrupación del voto por el interés del territorio. Pero sucede que, en las actuales circunstancias, sobreponerse a la lucha partidista exigiría una «revuelta» de los senadores designados por las instituciones territoriales contra sus partidos ${ }^{96}$. El problema que se plantea, en consecuencia, es que toda fórmula que recurra a una representación de Derecho público no es representativa en sentido estricto como consecuencia de la opuesta naturaleza de la representación política y la representación de Derecho público, que excluye toda representatividad ${ }^{97}$.

En un orden de consideraciones más general, la nueva reforma del Senado belga es ejemplo de cómo la crisis de las segundas cámaras ha pasado de la crisis de legitimidad que padecieron a comienzos del siglo $\mathrm{xx}$, a una crisis de identidad, pues la legitimidad democrática de su composición solo puede producir un bicameralismo clónico o especular, mientras que la representación especial, característica de las segundas cámaras territoriales, conduce a la paradoja de que para ganar en especialización las cámaras territoriales necesariamente ven reducidas sus competencias a tales mínimos, que dejan de ser cámaras permanentes, a lo que se debe sumar que, salvo en procedimientos de reforma constitucional, sus decisiones están supeditadas a la última palabra de la Cámara de Representantes. Ante tales paradojas, que imponen a las segundas cámaras, para poder subsistir, un drástico recorte de sus poderes, tanto en el ámbito material como en el funcional, parece sensato considerar si no son otras las razones por las que perviven muchas de las segundas cámaras, muy distintas en todo caso a razones de técnica legislativa o de legitimidades representativas complementarias. Cabe a este respecto recordar aportaciones doctrinales como la de Yves Weber ${ }^{98}$, quien en su momento ya constató que el bicameralismo había perdido su objeto, o la de Herrero de Miñón99, apuntando las disfuncionalidades del bicameralismo. Tal vez una de las claves que sin duda puede suministrarnos elementos para entender la funcionalidad actual de las segundas cámaras, especialmente las de Estados compuestos, pero también las de jóvenes democracias ${ }^{100}$, es la de su ca-

96 Cfr. C. VAn Wynsberghem, «The Belgian Senate: little damage, little use», Verfassungsblog, 23 Oktober 2014.

97 Vid. R. Chueca Rodríguez, «Condicionamientos constitucionales de la reforma del Senado», en J.M. Vidal Beltrán y M.A. García Herrera (cords.), El Estado Autonómico: integración, solidaridad y diversidad, vol. I, Madrid, Colex, 2005, p. 206.

98 Cfr. Yves Weber, «La crise du bicameralisme», Revuedu.DroitPublic, 1972, p. 592.

99 Cfr. Miguel Herrero de MiÑón, «The Passing of Bicameralism», The American Journal of Comparative Law, 1975, pp. 236 y ss.

100 Cfr. Alain Delcamp, «La seconde chambre commerévélateur de la nature de l'État», en Etudes en hommage à Francis Delpérée. Itinérairesd'unconstitutionnaliste, Bruylant, LGDJ, Bruxelles, 2007, p. 401. 
rácter de herramienta institucional de pacificación y conciliación, bien sea entre fuerzas políticas, bien sea entre centro y periferia, de manera que la función del bicameralismo no se reduce a lo estrictamente representativo, sino que la duplicidad de cámaras supone incorporar un dispositivo conciliador de intereses contrapuestos o la manera de asociar a la política nacional a los otros destinatarios, - aparte de los ciudadanos_- de la legislación, de modo que los entes sub-estatales devienen una suerte de destinatarios institucionales de las leyes, que legitiman con su participación las normas que se les aplican. Sin esta óptica, próxima a lo que cabe definir como políticas del bicameralismo, no sería del todo comprensible la continuidad de muchos de los parlamentos bicamerales actuales, sobre todo en un momento del ciclo de las democracias deliberativas en el que remedios deliberativos como los que encarna el bicameralismo parecen superados por dinámicas de variado signo, muchas de ellas vinculadas a la búsqueda de mecanismos de participación extra-institucionales ${ }^{101}$ y al replanteamiento de duplicidades prescindibles.

\section{$* * *$}

TITLE: More Dependent and less Competent: the new Belgian Senate after the Constitutional Reform

ABSTRACT: The Belgian Senate has only not been alien to the transformations of Belgian federalism, but in each of the constitutional revisions that have taken place since 1831, its composition has always been subject to change. So, in the midst of a political and institutional crisis following the federal elections of 2010, the post-election government formation and agreements forged institutional Agreement to the Sixth state reform of October 11, 2011, which has involved a constitutional revision and a broad legislative implementation that has affected many aspects of the territorial and institutional organization. The aim of this reform of the Senate, according to the preamble of the reform, is to ensure the participation of the parliaments of the federated entities (regions and linguistic communities) to the organization and functioning of the federal state and create a real linkage for Community and Regional Parliaments. One of the most important changes of this Senate reform is given by the abolition of the direct election of senators. On the other hand, by excluding the Senate legislative procedure on matters other than those expressly mentioned in arts. 77 and 78 of Belgian Constitution, the reform has created a residual legislative power for the House of Representatives, making unicameralism the general rule and bicameralism the exception. Senate resulting from this reform represents a break with the Senate that is left behind. Even so, the resulting Senate is not comparable to any known federal model. Nevertheless, the weakest aspect of this reform is that usual to reforms of second chambers, which is to fail to territorialize the vote of the senators, because in so far as the vote continues to have a political affiliation, the territory that they represent is not thinkable as a subject represented.

RESUMEN: El Senado belga no solo no ha sido desde luego ajeno a las transformaciones del federalismo belga, sino que en todas y cada una de las revisiones constitucionales que han tenido lugar desde 1831 su composición ha sido siempre objeto de modificación. En medio de una crisis política e institucional tras las

101 En efecto, mediante otros mecanismos que van desde las mayorías reforzadas en un Parlamento unicameral, hasta las cuotas representativas igualitarias;o desde las minorías de veto hasta los referéndums consultivos o abrogativos, son variadas las fórmulas, bien sea para garantizar una representación de los intereses territoriales sin necesidad de una segunda cámara, o bien para trasladar a una segunda decisión o propiciar una reconsideración de las disposiciones a adoptar. 
elecciones legislativas federales de 2010, los acuerdos post-electorales y de formación de gobierno forjaron el Acuerdo institucional para la sexta reforma del Estado de 11 de octubre de 2011, cuya traducción normativa ha entrañado una reforma constitucional y legislativa de amplio espectro que ha incidido en numerosos aspectos de la organización territorial e institucional. El objetivo perseguido con esta reforma del Senado según la exposición de motivos de la reforma es el de garantizar la participación de los parlamentos de los entes federados a la organización y funcionamiento fundamentales del Estado federal, así como crear un vínculo real de encuentro para los Parlamentos de Comunidad y de Región. Uno de los cambios más trascendentes de esta reforma del Senado viene dado por la desaparición de la elección directa de senadores. Al excluir al Senado del procedimiento legislativo sobre materias que no sean las expresamente mencionadas en los arts. 77 y 78 CB, la reforma ha creado una potestad legislativa residual para la Cámara de Representantes, haciendo del monocameralismo la regla general y del bicameralismo la excepción. el Senado resultante de la reforma supone una ruptura respecto a al Senado que se deja atrás. Aun así, el Senado resultante no puede asimilarse a ninguno de los modelos federales conocidos. El flanco más débil de esta reforma no obstante es el mismo que está asociado a todas las reformas de las segundas cámaras que no logran territorializar el voto de los senadores, ya que en la medida en que el voto siga teniendo una afiliación política, no es dable reconocer como sujeto representado al territorio al que representan.

KEY WORDS: Belgian Senate,bicameralism, territorialrepresentation, federalism, Belgian Constitution.

Palabras Clave: Senado belga, Bicameralismo, Representación territorial, Federalismo, Constitución belga.

FECHA DE RECEPCIÓN: 21.12.2015 FECHA DE ACEPTACIÓN: 27.07.2016 